\title{
Heterogeneous bedrock investigation for a closed-loop geothermal system: A case study
}

\author{
G. Radioti ${ }^{\mathrm{a}, \mathrm{b}, *}$, S. Delvoie ${ }^{\mathrm{a}}$, R. Charlier ${ }^{\mathrm{a}}$, G. Dumont ${ }^{\mathrm{a}}$, F. Nguyen ${ }^{\mathrm{a}}$ \\ a ArGEnCo department, University of Liege, Allée de la Découverte 9, 4000 Liege, Belgium \\ ${ }^{\mathrm{b}}$ F.R.I.A, F.R.S-F.N.R.S., Rue d'Egmont 5, 1000 Brussels, Belgium
}

\section{A R T I C L E I N F O}

\section{Article history:}

Received 3 September 2015

Received in revised form 2 February 2016

Accepted 11 March 2016

\section{Keywords:}

Bedrock heterogeneity

High-resolution temperature

measurements

Borehole televiewer

Cuttings thermal conductivity

Closed-loop geothermal systems

\begin{abstract}
A B S T R A C T
This paper investigates bedrock heterogeneity by applying three different geophysical approaches, in order to study the long-term behaviour and the interaction between closed-loop geothermal systems. The investigated site consists of four boreholes equipped with geothermal pipes on the campus of University of Liege, Belgium. The first approach includes acoustic borehole imaging, gamma-ray logging and cuttings observation and results to a detailed fracture characterisation, rock identification and layer dip angle determination. The second approach consists of measuring the thermal conductivity of cuttings at the laboratory. Study of cuttings thermal conductivity measurements can contribute to bedrock heterogeneity knowledge concerning the transition of one formation to another and the layer dipping. The third approach is based on high-resolution temperature profiles, measured during the hardening of the grouting material and the recovery phase of a Distributed Thermal Response Test. Through this approach a correlation of the temperature profiles to the geological characteristics of the surrounding bedrock is identified. The analysis of this correlation can provide information on fractured zones, alternation of different rock types and layering dipping. This latter approach can be easily applied on closed-loop geothermal systems to characterise the bedrock and investigate its heterogeneity as well as contribute to the their long-term behaviour prediction and to the optimisation of their efficiency.
\end{abstract}

(c) 2016 Elsevier Ltd. All rights reserved.

\section{Introduction}

The characterization of rock properties and of their heterogeneity is critical in many engineering geology applications, in particular for geothermal systems where thermal properties control the geothermal reservoir behaviour. This knowledge of the subsurface can be used to determine geothermal targets or design underground heat exchange systems at the regional or local scale (Fuchs and Förster, 2010). Lithological variations, mineralogy (in particular quartz content), uneven distribution of fractures, the presence of faults and tectonic structures and varying dip angle contribute to the heterogeneity of the bulk rock thermal properties in addition to variations in the water content and porosity (Guéguen and Palciauskas, 1994). Therefore, a detailed bedrock characterisation is crucial for understanding and predicting the thermal behaviour of the rock mass in-situ.

Several methods have been developed in order to characterise the bedrock at the laboratory scale, using rock samples or cut-

\footnotetext{
* Corresponding author.

E-mail address: gradioti@ulg.ac.be (G. Radioti).
}

tings. Core samples or cuttings can be studied to obtain lithology and textural data (Bradbury et al., 2007), but provide limited or no information on fracturing. Several studies include measurement of thermal properties at rock samples to investigate the influence of various factors, such as mineral composition, porosity and degree of saturation (Clauser and Huenges, 1995; Popov et al., 1999; Pechnig et al., 2010). However, extrapolating those results to in-situ conditions remains challenging (Liebel et al., 2010).

On the other hand, borehole logging may provide more representative information of in-situ conditions. Borehole geophysical methods are used for site characterisation such as gamma-ray logging, resistivity logging, flow meter testing, seismic logging and borehole imaging (Monier-Williams et al., 2009). These methods can provide information on lithology, stratigraphy and fracturing (Keys, 1990) of the rock locally surrounding the borehole. Fujii et al. (2006) and Acuña (2010) investigated anisotropic thermal behaviour by conducting Distributed Thermal Response Tests (DTRT) in Borehole Heat Exchangers (BHEs). In both of these works, the authors analysed temperature profiles during the heat injection and recovery phase of the test to study the distribution of effective thermal conductivity through depth. Laloui et al. (2003) installed thermometers in a heat exchanger pile passing through 
different soil layers to study its thermo-mechanical behaviour. Fujii et al. (2009) used optical fiber sensors to record vertical temperature profiles in two bedrock case-studies in Japan and related these results with local geological and groundwater information, to verify the validity of the test and interpretation method. In the first case a permeable granite zone of $10 \mathrm{~m}$ thick was related to higher calculated thermal conductivity and quicker temperature recovery compared to non-permeable granite, as an effect of an active groundwater flow. In the second case lower thermal conductivity was related to weathered tuff, compared to unweathered tuff. Liebel et al. (2011) studied non-grouted wells in Norway and proposed taking temperature measurements four to five hours after the beginning of the recovery phase. They related faster temperature recovery to hydraulically active fractures and upcoming groundwater flow from confined artesian aquifers, as an effect of groundwater flow. They verified the existence of fractures by using flow measurement test data, televiewer imaging and/or drillers reports. The correlations provided in these studies concern distinct thick rock layers and/or are based on groundwater flow effects.

The objective of this paper is to characterise the heterogeneity of rock in-situ in the absence of high groundwater flow based on high-resolution temperature measurements and on rock thermal behaviour knowledge. We studied high-resolution temperature profiles, measured by fiber optics, in four BHEs (namely B1-B4) filled with grouting material, installed over a surface area of $32 \mathrm{~m}^{2}$ in an heterogeneous bedrock in Belgium. We located fractured zones more than one meter thick based on temperature profiles during hardening of the grouting material. We related temperature profiles measured during the recovery phase to thin rock layers of different mineral content (thickness more than $1.2 \mathrm{~m}$ ) and determined the layer dip angle. We evaluated the correlations through a detailed geological description resulting from borehole logging measurements conducted in the four boreholes. Moreover, we measured the thermal conductivity of cuttings at the laboratory and correlated the measurements with the in-situ observations in terms of thermal conductivity and layering.

The remainder of the paper is organised as follows. First the geological background of the site is presented together with the materials and methods used in this study. Then a characterisation of the bedrock heterogeneity (including fracture characterisation, rock identification and layer dip angle determination) based on borehole logging measurements follows. The laboratory measurements of cuttings thermal conductivity are presented and their extrapolation to the in-situ conditions is discussed. The fiber optic measurements and their correlation to the rock characteristics as indicated by the borehole logging results follow. Finally conclusions are provided as well as a discussion on the accuracy of the fiber optic measurements analysis and its possible applications.

\section{Site set-up}

\subsection{Geological settings and BHEs installation}

The investigated site is located in the north-east side of the Dinant Synclinorium geological structure. The geological map of Sart-Tilman (Calembert et al., 1964) provides the most recent published geological interpretation of the bedrock for the studied area (Fig. 1). The site is also located on the North side of a local syncline. The synclinal axis has an E-W orientation. Based on the geological map, the boreholes cross Emsian (Lower Devonian) detrital sedimentary rocks, probably corresponding to Wépion Formation and Burnot Formation. Both formations include alternations of shale, siltstone, sandstone and quartzite. Some of these layers are lenticular. From a general point of view, the Burnot Formation is mainly composed of red sediments while the Wépion Formation is mainly made up of green layers. However, detailed studies show that red layers are not rare into the Wépion Formation and some green beds can be met in the Burnot Formation (Corteel et al., 2004; Bultynck et al., 1991). The lack of easily observable differences between these two Formations makes their distinction very difficult.

The subsurface sediments are well documented in the geotechnical map of Sart-Tilman (Calembert et al., 1975). This map includes data from two boreholes located in a distance smaller than $200 \mathrm{~m}$ from the investigated site. Lithological logs of the two boreholes indicate deposits of silt, sand and gravel until a depth of approximately $7 \mathrm{~m}$. A layer of altered bedrock of a thickness approximately $3 \mathrm{~m}$ follows. The non-altered bedrock starts at a depth of approximately $10 \mathrm{~m}$.

In order to obtain a detailed bedrock characterisation and to investigate the influence of heterogeneity on thermal rock behaviour in-situ, four boreholes equipped with double-U geothermal pipes of $100 \mathrm{~m}$ long, were installed on the campus of the University of Liege (Liege, Belgium) over a surface area of $32 \mathrm{~m}^{2}$ (Fig. 2) (Radioti et al., 2013). The boreholes of a diameter of $135 \mathrm{~mm}$ were drilled by using a DTH hammer bit (destructive drilling technique) and cuttings were collected during the drilling. Moreover, the boreholes were supported with casing at the first top meters (15.5 $\mathrm{m}$ for B1, $13.5 \mathrm{~m}$ for B2 and $9.5 \mathrm{~m}$ for B3 and B4) to keep loose soil from collapsing into the borehole. After the drilling, a borehole televiewer was lowered into the four boreholes. Then fiber optic cables were attached along the pipe loops and the double$\mathrm{U}$ pipes were lowered into the boreholes. Finally, the boreholes were backfilled with the following grouting materials: two of them with a silica sand-based commercial material (Geosolid), one with a bentonite-based commercial material (Füllbinder) and one with a homemade admixture with graphite. Erol and François (2014) presented a detailed laboratory characterisation of these materials, including the following thermal conductivity values of grout samples: $2.35 \mathrm{~W} / \mathrm{mK}$ for Geosolid, $0.95 \mathrm{~W} / \mathrm{mK}$ for Füllbinder and $2.5 \mathrm{~W} / \mathrm{mK}$ for the homemade admixture with graphite.

\subsection{Materials and methods}

\subsubsection{Borehole logging}

The first approach consists in lowering a borehole televiewer (Zemanek et al., 1970) into the boreholes to obtain high-resolution, continuous images with $360^{\circ}$ Coverage of the local geology and fracturing. A borehole televiewer is composed of a transducer which is rotated $360^{\circ}$ while lowered down inside the borehole. An in-line centralizer allows the tool to be centered during the measurement procedure. The transducer transmits ultrasonic pulses $(1.5 \mathrm{MHz})$, which travel through the drilling mud and undergo partial reflection at the borehole wall, and receives the reflected pulses. The acoustic travel time and amplitude data are recorded. The acoustic travel time depends on the borehole radius and the acoustic amplitude depends on the soil/rock impedance.

In our experiment, azimuth and deviation were constantly measured by magnetometers and inclinometers (Monier-Williams et al., 2009). The inclination of the borehole at each point was calculated based on the moving average of these data over an interval of $10 \mathrm{~cm}$, with an orientation precision of $\pm 0.5^{\circ}$ and $\pm 1.0^{\circ}$ for the inclination and the azimuth respectively. The travel time and amplitude data were oriented with respect to the Magnetic North and converted into colorized, continuous images with $360^{\circ}$ coverage of the borehole wall. Moreover natural-gamma radiation emitted by the rocks surrounding the boreholes was measured every $5 \mathrm{~cm}$. Based on the borehole logging data a detailed fracture characterisation (position, opening, orientation, dip angle) can be obtained (Paillet et al., 1990; Williams and Johnson, 2004). Gamma-ray data and observation of the cuttings during drilling may result in rock identification through depth (Keys, 1990). This procedure was applied 


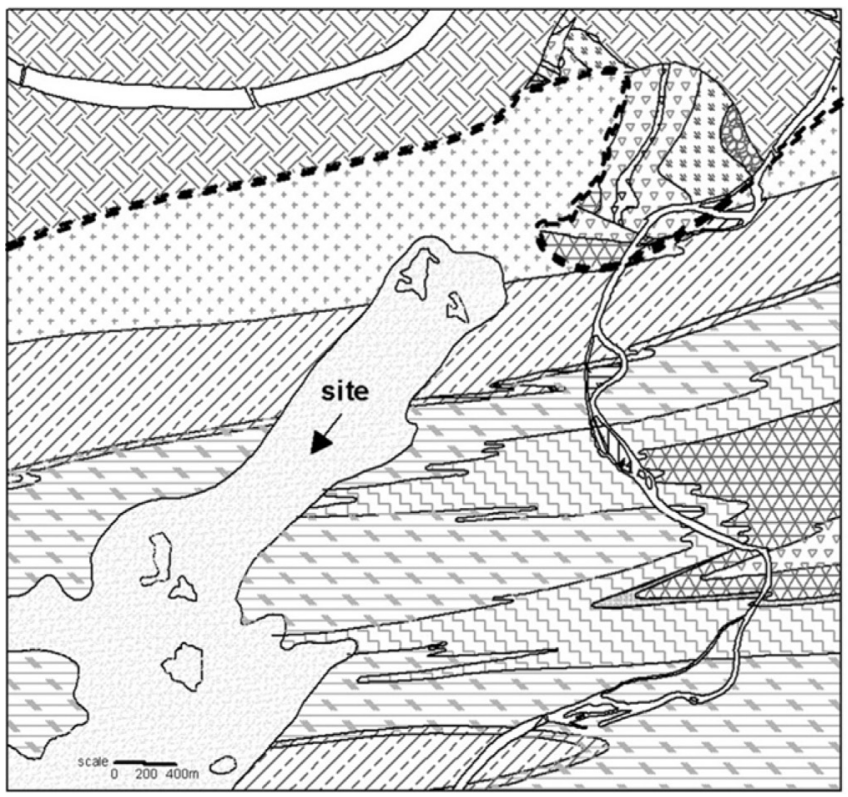

\begin{tabular}{|c|c|}
\hline & Sand \\
\hline बisy & Westphallen-Namurian \\
\hline 8000 & Tournalsian \\
\hline 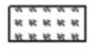 & Famennian sup. \\
\hline 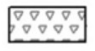 & Famennian inf. \\
\hline$X A$ & Frasnian \\
\hline & Eifelian (Couvinian)-Giventian \\
\hline & Emsian 2-3 sup. \\
\hline 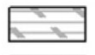 & Emsian $2-3$ inf. \\
\hline EIIT & Emsian 1 \\
\hline 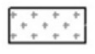 & Praglan (Slegenian) \\
\hline$==$ & Eifellan fault \\
\hline
\end{tabular}

Fig. 1. Geological map of the Sart Tilman area (Calembert et al., 1964).
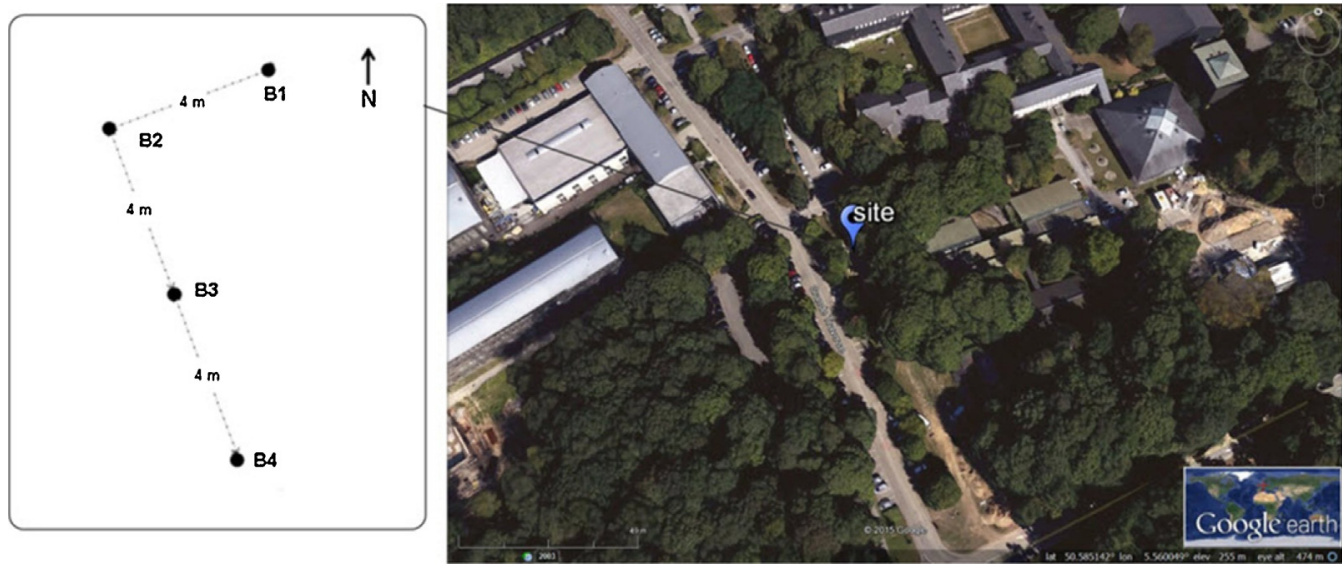

Fig. 2. Position of the four BHEs in the cadastral parcel Liege 26th division, section C, $\mathrm{n}^{\circ} 49 \mathrm{~S} 3$ (retrieved from Google Earth ${ }^{\odot}$ ).

to the four boreholes in order to investigate the uneven distribution of fractures in the rock mass and to determine the layer dipping.

\subsubsection{Thermal conductivity of cuttings}

The second approach consists in measuring the thermal conductivity of cuttings at the laboratory, commonly used for geothermal applications (Alonso-Sánchez et al., 2012). Sampling containers were used to collect cuttings during the drilling. In each container, cuttings corresponding to a depth interval ranging between $2 \mathrm{~m}$ and $6 \mathrm{~m}$ were gathered. From each container 1-5 dry independent samples were prepared at the laboratory (Fig. 3a). The uncertainty of each sample's corresponding depth ${ }^{1}$ depends on the sampling depth interval of each container. The measured thermal conductivity values of the samples in each container were assigned to the average corresponding depth of the container. The thermal conductivity of 21 samples for B3 and 25 samples for B4 was measured at the laboratory by applying the needle probe technique (ASTM D 5334-00, 2000). Theoretically, the temperature rise in an infinite homogeneous medium due to an infinite line source is measured.

\footnotetext{
1 i.e., the depth at which the sample was collected.
}

In practice, the infinite soil mass is replaced by a large cylinder (of a height of $0.170 \mathrm{~m}$ and a diameter of $0.064 \mathrm{~m}$ in this study) and the infinite line source is replaced by a thermal needle probe, a device that consist of a heating wire and a temperature measuring element. The needle, of a diameter of $1.5 \mathrm{~mm}$ in this study, is connected to a device that produces a constant current and a device that produces a digital readout of temperature. The needle is inserted in the centre of the sample cylinder and a known constant current is applied to the heater wire for sufficient long time (Fig. 3b). During this time the temperature rise is recorded.

The sample's thermal conductivity, $\lambda_{\text {sample }}(W / m K)$, is calculated from the quasi steady-state portion of the temperature profile as:

$\lambda_{\text {sample }}=\frac{Q}{4 \pi \Delta T} \Delta \ln t$,

where $T$ is the temperature $\left({ }^{\circ} \mathrm{C}\right), \mathrm{t}$ is the time $(\mathrm{s})$ and $\mathrm{Q}$ is the heat input $(W / m)$. The heat input is calculated as $Q=I^{2} R / L$, where $I$ is the applied constant current $(A), R$ is the total resistance of the heater wire $(\Omega)$ and $L$ is the length of the heater wire $(m)$. The thermal conductivity of the cuttings samples was measured at room temperature and for a heat input of approximately $6 \mathrm{~W} / \mathrm{m}$. 
a)

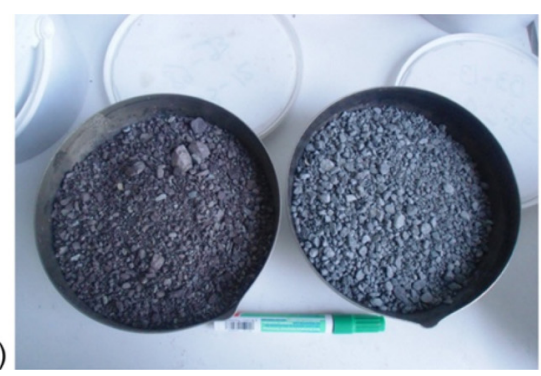

b)

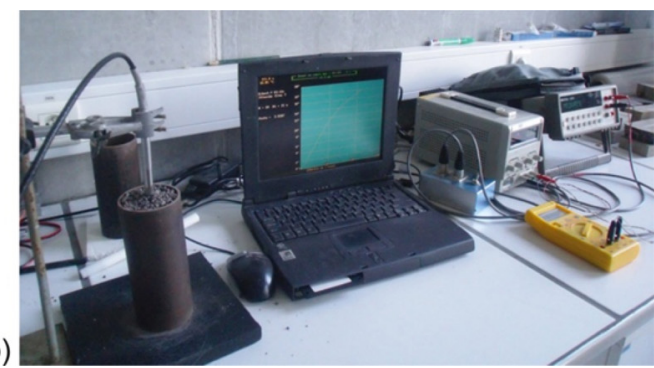

Fig. 3. a) Cuttings corresponding to wine-red shale/siltstone and grey sandstone layers b) thermal needle probe equipment.

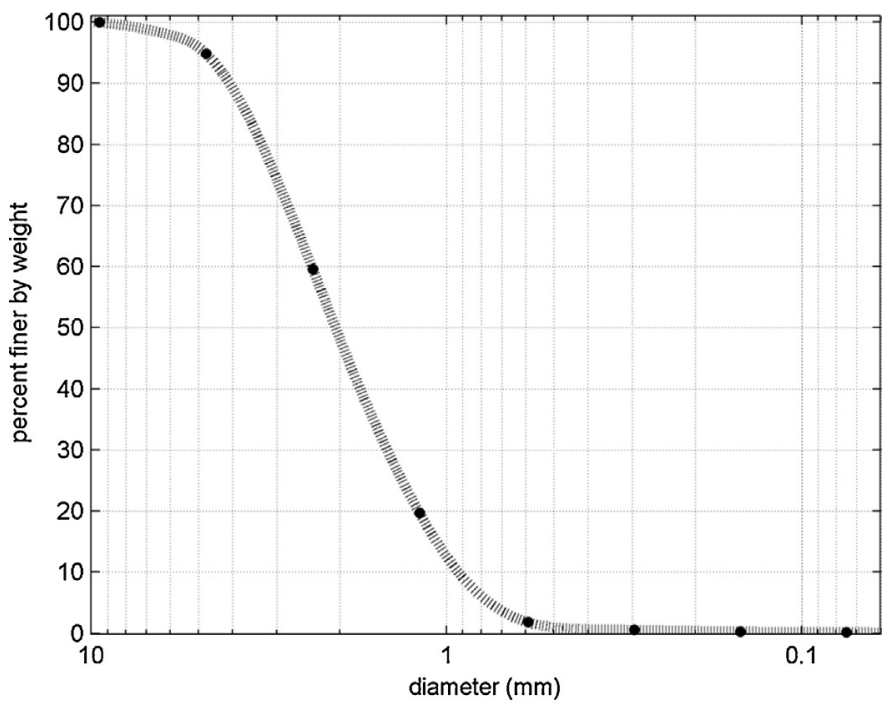

Fig. 4. Grain size distribution of cuttings.

Considering the sample a two-phase material consisting of the solid phase (cuttings) and air phase, the cuttings thermal conductivity, $\lambda_{\text {cutt }}(W / m K)$, can be calculated by means of the sample's porosity, $n$, as (Alonso-Sánchez et al., 2012):

$\lambda_{\text {cutt }}=\left(\lambda_{\text {sample }} / \lambda_{\text {air }}\right)^{1 /(1-n)}$,

where air thermal conductivity is taken as $\lambda_{\text {air }}=0.025 \mathrm{~W} / \mathrm{mK}$.

For an accurate measurement the cuttings grain size should not significantly exceed the needle diameter (Kömle et al., 2010). In this study $33 \%$ of the cuttings is finer than the needle diameter $(1.5 \mathrm{~mm})$ and $92 \%$ finer than 3 times the needle diameter $(4.5 \mathrm{~mm})$, as presented in Fig. 4.

\subsubsection{Distributed temperature sensing (DTS) technique and DTRT procedure}

The third approach consists in measuring the temperature along the borehole length. After drilling the boreholes, fiber optic cables were attached along the pipe loops and the double-U pipes were lowered into the boreholes. Temperature is measured along the fiber optics, by applying the DTS technique (Soto et al., 2007). This technique is based on Raman optical time domain reflectometry (Dakin and Pratt, 1985). A laser pulse is injected into the optical fiber and the light is scattered and reemitted from the observed point. The backscattered light is spread across a range of wavelengths. The Raman backscatter signal is temperature sensitive. The temperature along the fiber is determined by the intensity of Raman Stokes and anti-Stokes signals. The position of the temperature reading is determined by the arrival time of the reemitted light pulse. The temperature resolution (standard deviation) was in the order of $0.05^{\circ} \mathrm{C}$. Temperature was recorded every $20 \mathrm{~cm}$ (sampling inter- val) with a spatial resolution of $2 \mathrm{~m}$. Spatial resolution determines the slope width of a measured temperature change and is an important parameter for the temperature accuracy of local hotspots. If the width of the hotspot is lower than the spatial resolution, the measured temperature is reduced by approximately the ratio of hotspot width to spatial resolution (Hoffmann et al., 2007).

Temperature was measured during hardening of the grouting material, at the undisturbed state and during the recovery phase of a DTRT. The typical equipment for a TRT (Gehlin, 2002) consists of a pump (to circulate the fluid inside the pipes), an electric resistance heater (to inject constant heat), temperature sensors (to measure the temperature) and a data logger (to record the measurements during the test). The equipment is connected to the BHE pipes and insulation layers are attached around the pipes to minimize the heat transfer between the circulating fluid and the air. Before starting the test, water is circulated at high flow rate to purge air from the system. After purging the air the first phase of the test starts. During this phase water is circulated inside the pipe loop to achieve equilibrium between the water and the surrounding ground. The second phase consists of a continuous water circulation with usually constant heat input. After the heating period, the system is left to recover to its undisturbed state. During the test temperature is recorded at the pipe inlet and outlet. Based on the measured data the mean thermal conductivity of the surrounding ground and the mean borehole thermal resistance can be calculated. During a DTRT temperature is measured not only at the pipe inlet and outlet but also at different depths along the borehole (Fujii et al., 2006). Our experimental site allows us to obtain continuous high-resolution temperature profiles along the borehole length thanks to the fiber optics.

\section{Results}

\subsection{Borehole logging}

The televiewer measurements were conducted at depths beneath $15.55 \mathrm{~m}$ for $\mathrm{B} 1,13.50 \mathrm{~m}$ for B2, $10 \mathrm{~m}$ for B3 and $10.46 \mathrm{~m}$ for B4, since the boreholes were supported with casing at the first top meters to keep loose soil from collapsing into the borehole. The bottom depth was $98.67 \mathrm{~m}$ for B2, $102 \mathrm{~m}$ for B3 and $96.44 \mathrm{~m}$ for B4. For B1 the bottom depth was limited to $75.28 \mathrm{~m}$, since collapsed rock pieces had blocked the borehole at that depth. The following results correspond to above depth intervals.

\subsubsection{Fracture characterisation}

Fig. 5 shows high-resolution images of the acoustic signal travel time and amplitude for an extended and a slightly fractured zone. Black zones in the travel time column correspond to low travel time values and white zones to high travel time values. Yellow zones in the amplitude column correspond to high amplitude values and indicate the existence of dense soil or rock. Blue zones correspond to low amplitude values and indicate fractures, altered rock or soft soil. Random blue spots indicate locally broken rock due to the 

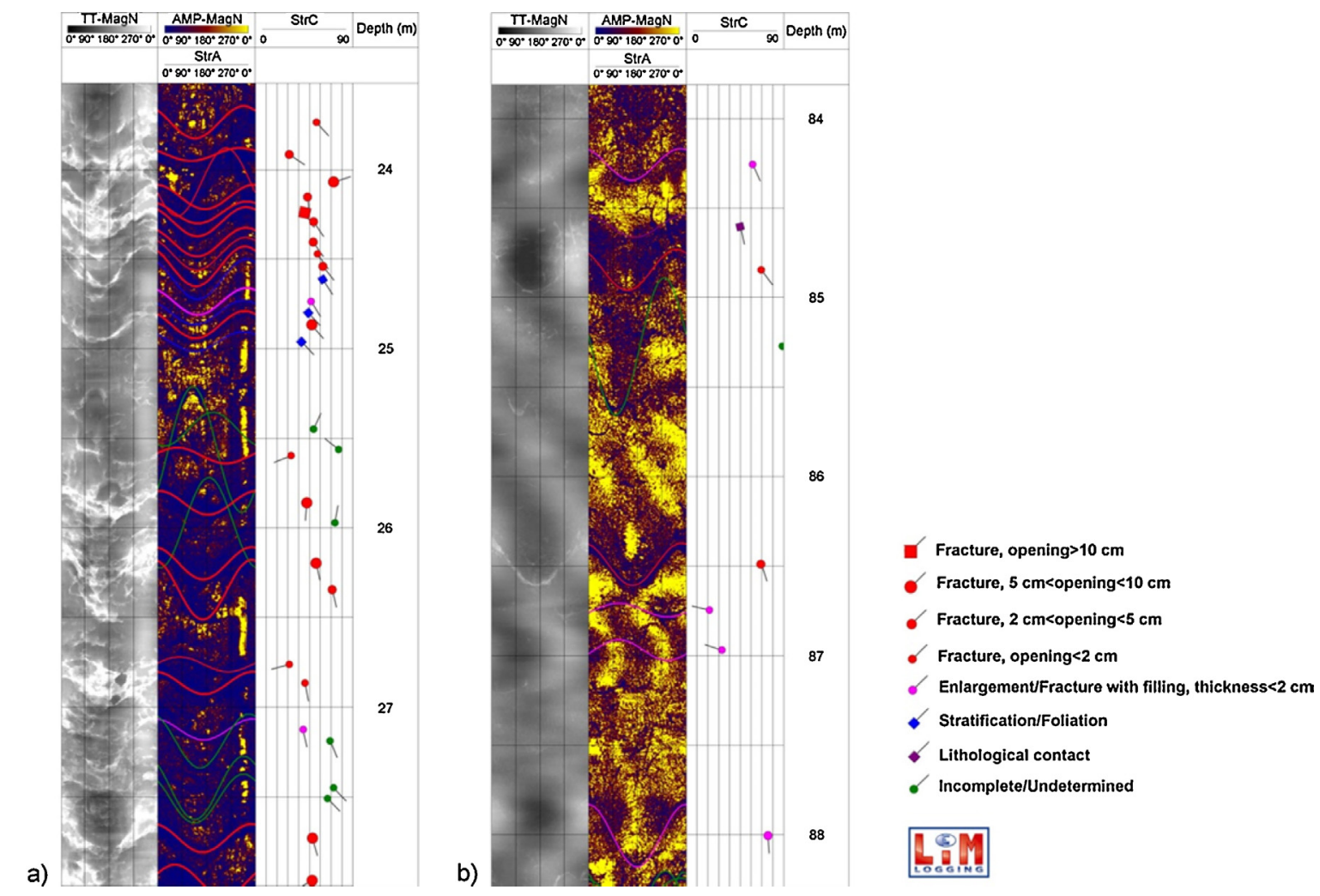

Fig. 5. High-resolution images of a) extended fractured zone in B4 and b) slightly fractured zone in B2, from left to right: acoustic travel time column, acoustic amplitude column, structural interpretation of each fracture (opening, orientation, dip angle) and corresponding depth values.

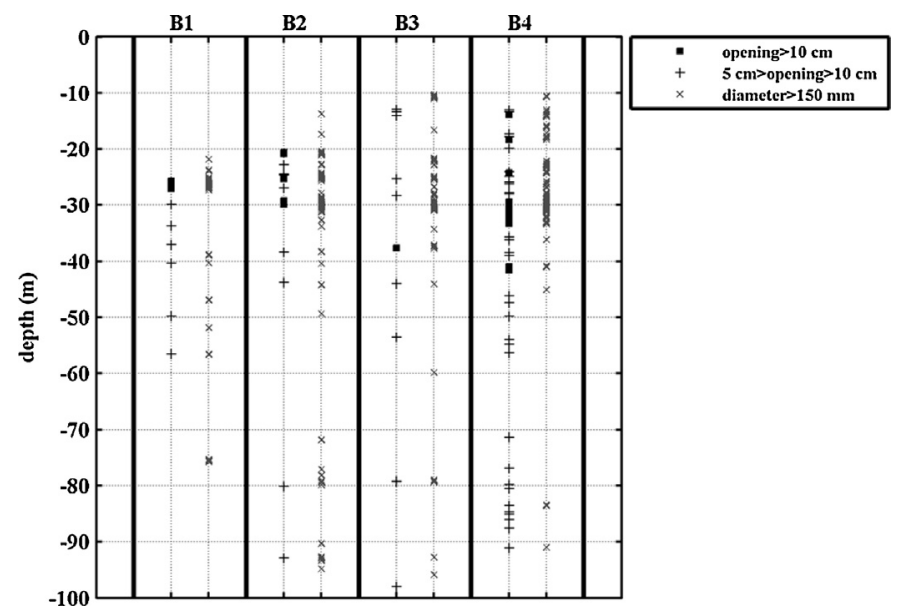

Fig. 6. Distribution of open fractures and borehole diameter larger than $150 \mathrm{~mm}$ for the four boreholes.

drilling. Shaped curves on the images plot represent planes over a fracture or bedding trace. Based on these data each element is interpreted as an open fracture, a fracture with filling, a stratification/foliation or a lithological contact. We note that the distinction between different elements is not always obvious. For example a fracture with filling could be misinterpreted as stratification.

The distribution of open fractures more than $5 \mathrm{~cm}$ wide for the four boreholes, based on the logging interpretation, is shown in Fig. 6. Based on these data, fractures significantly vary in number and location in the four boreholes, despite the close distance between them. B4 is more fractured than the other three boreholes, consisting of 12 fractures more than $10 \mathrm{~cm}$ wide and 31 fractures of an opening between $5 \mathrm{~cm}$ and $10 \mathrm{~cm}$. B3 seems the less fractured, consisting of one fracture more than $10 \mathrm{~cm}$ wide and 10 fractures of an opening between $5 \mathrm{~cm}$ and $10 \mathrm{~cm}$. Moreover, extended zones (more than one meter thick) of large fractures (opening > than $10 \mathrm{~cm}$ ) are observed in B1 and B4, between $25.6 \mathrm{~m}$ and $27.1 \mathrm{~m}$ and $29.4 \mathrm{~m}$ and $31.3 \mathrm{~m}$ depth respectively. B2 is characterised by a smaller fractured zone of $70 \mathrm{~cm}$ between $29.2 \mathrm{~m}$ and $29.9 \mathrm{~m}$ depth. These results indicate also that the extension of some fractures in space is limited.

The depth position where the borehole diameter is larger than $150 \mathrm{~mm}$ (equal to hammer bit diameter plus $20 \mathrm{~mm}$ ) is also shown in Fig. 6. These measurements could indicate extended fractured zones of more than one meter thick, between approximately $25 \mathrm{~m}$ and $27 \mathrm{~m}$ for B1, between $24 \mathrm{~m}$ and $31 \mathrm{~m}$ depth for B2, $29 \mathrm{~m}$ and $31 \mathrm{~m}$ depth for B3 and between $28 \mathrm{~m}$ and $34 \mathrm{~m}$ for B4.

Fig. 7 shows the stereographic projection of the pole of each discontinuity for the four boreholes (Wulff net). The dip angle of most fractures varies between $40^{\circ}$ and $70^{\circ}$ /horizontal and the orientation varies between $\mathrm{N} 40^{\circ}$ and $\mathrm{N} 80^{\circ}$ for all the boreholes. The median average dip angle is approximately $52^{\circ}$ /horizontal for B1, $54^{\circ}$ /horizontal for B2 and 58 /horizontal for B3 and B4. The median average orientation is approximately $\mathrm{N} 57^{\circ}$ for $\mathrm{B} 1, \mathrm{~N} 60^{\circ}$ for $\mathrm{B} 2$ and $\mathrm{B} 3$ and $\mathrm{N} 61^{\circ}$ for $\mathrm{B} 4$.

\subsubsection{Rock identification}

Natural gamma radiation along the borehole was measured every $5 \mathrm{~cm}$ to characterise the clay content of the rock formation. Moreover cuttings were collected during the borehole drilling. The gamma-ray data and observation of the drill cuttings result in a detailed rock identification through depth. The bedrock consists mainly of siltstone and shale interbedded with sandstone layers, ranking between a few centimeters to a few meters $(<5 \mathrm{~m})$ thick, for the upper $65 \mathrm{~m}$ in B1, $72 \mathrm{~m}$ in B2, $75 \mathrm{~m}$ in B3 and $80 \mathrm{~m}$ in B4. The remaining parts of the boreholes are dominated by sandstone layers more than $5 \mathrm{~m}$ thick. Approximately the same lithostartigraphy is observed in the four boreholes, but at different depths. Varia- 

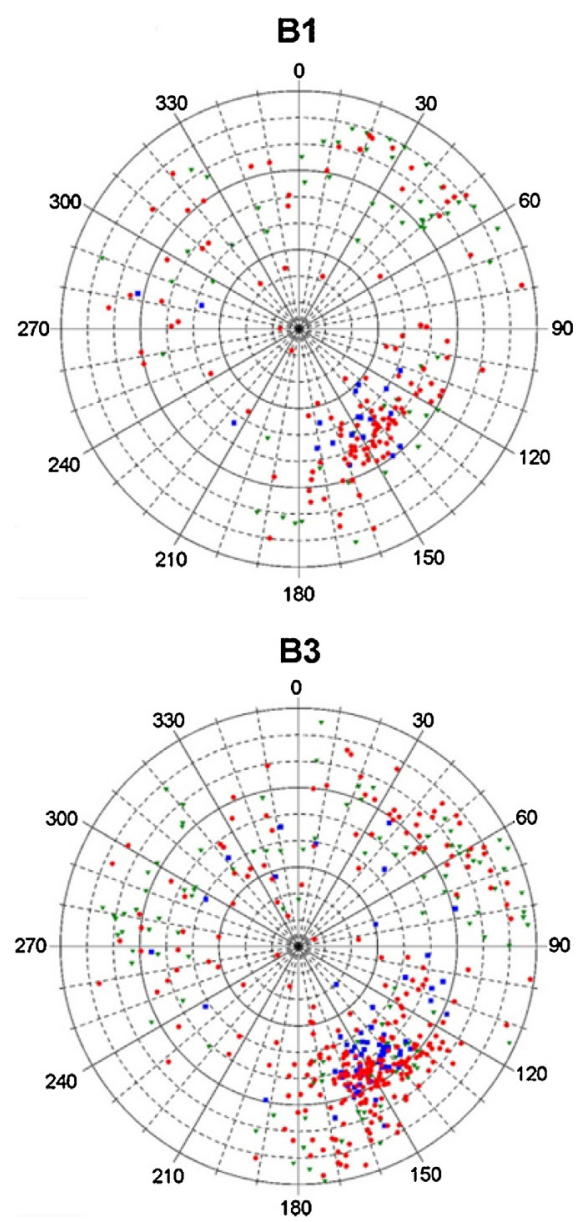
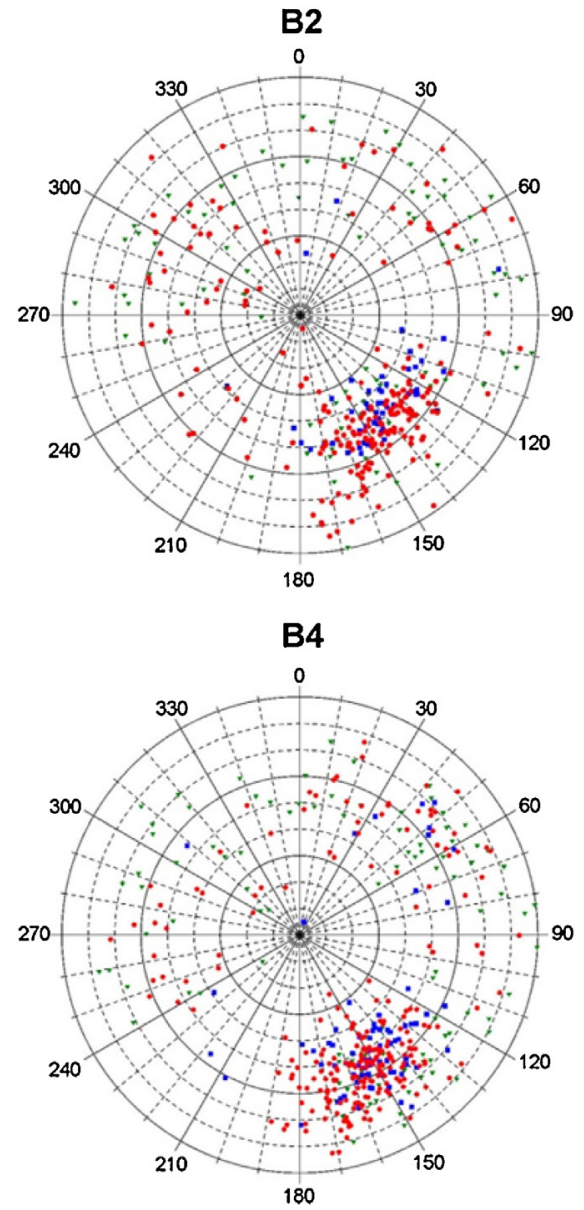

Fractures Stratification/Foliation/Contact Incomplete/Undetermined

Fig. 7. Structural data projection of the pole of each discontinuity on the upper hemisphere for the four boreholes.

Table 1

Layer dip angle calculation based on gamma-ray data.

\begin{tabular}{lllll}
\hline depth at B2 $(\mathrm{m})$ & 50.30 & 56.30 & 71.30 & 81.20 \\
& B2B3 & & & \\
horizontal distance $(\mathrm{m})$ & 3.23 & 3.07 & 2.75 & 2.61 \\
elevation difference $(\mathrm{m})$ & 3.30 & 3.10 & 2.70 & 2.70 \\
dip angle $\left(^{\circ}\right)$ & 45.62 & 45.32 & 44.53 & 45.96 \\
& B3B4 & & & \\
horizontal distance $(\mathrm{m})$ & 2.95 & 2.85 & 2.98 & 3.24 \\
elevation difference $(\mathrm{m})$ & 2.90 & 2.70 & 3.10 & 3.50 \\
dip angle $\left({ }^{\circ}\right)$ & 44.54 & 43.55 & 46.15 & 47.18 \\
mean dip angle $\left(^{\circ}\right)$ & 45.36 & & &
\end{tabular}

tions in the thickness of the layers (in the order of a few meters) are observed based on the analysis of each borehole.

Fig. 8 shows gamma-ray data and geological information that can be obtained based on the two procedures for the last $60 \mathrm{~m}$ of B4. High gamma-ray values in Fig. 8 ( $>80 \mathrm{cps})$ indicate shale/siltstone layers while low values $(<80 \mathrm{cps})$ indicate sandstone layers. The combination of the two procedures provides information on the rock type and the exact location of even thin rock layers with a resolution of $5 \mathrm{~cm}$.

\subsubsection{Layer dip angle determination}

Fig. 9 shows gamma-ray data for the four boreholes. It is observed that the same local peaks (dots in Fig. 9) are repeated at different depths in the four boreholes. Based on these data and the relative distance between the boreholes, the mean layer dip angle can be calculated (Table 1 ). The mean layer dip angle value, approximately $45^{\circ} \mathrm{SE}$, is included in the discontinuities dip angle range $\left(40-70^{\circ}\right)$ as indicated by the stereographic interpretation. Based on this, we may also conclude that the discontinuities presented in the stereographic interpretation are mainly related to stratification discontinuities.

The deviation of the four boreholes is shown in Fig. 10. The inclination of the boreholes increases progressively through depth (with a value of $6.82^{\circ}$ in $\mathrm{B} 1$ at $75.8 \mathrm{~m}, 10.67^{\circ}$ in $\mathrm{B} 2$ at $98.6 \mathrm{~m}, 13.69^{\circ}$ for B3 at $102.1 \mathrm{~m}$ and $12.90^{\circ}$ in $\mathrm{B} 4$ at $96.4 \mathrm{~m}$ ) and tends to be perpendicular to the layer stratification.

\subsection{Thermal conductivity of cuttings}

Cuttings were collected during drilling and dry samples were prepared at the laboratory. Fig. 11 shows the measured thermal conductivity of the cuttings for B3 and B4, where each sample was assigned to the average corresponding depth of the container. It is observed that high thermal conductivity values, indicated with grey colored diamonds, correspond to mainly sandstone/siltstone layers (low gamma-ray values). Low thermal conductivity values, indicated with black colored circles, correspond to mainly shale/siltstone layers (high gamma-ray values). Sandstone is mainly composed of quartz and feldspar while shale and siltstone contain a significant clay fraction. The thermal conductivity of quartz, $\lambda_{\text {quartz }}=7.7 \mathrm{~W} / \mathrm{mK}$, is much higher than the one of non-quartz minerals, $\lambda_{\text {non-quartz }}=1.5-5.0 \mathrm{~W} / \mathrm{mK}$, (Clauser and Huenges, 1995). As a result the sandstone/siltstone thermal conductivity is increased compared to the shale/siltstone thermal conductivity. In this case the transition of one formation to another 


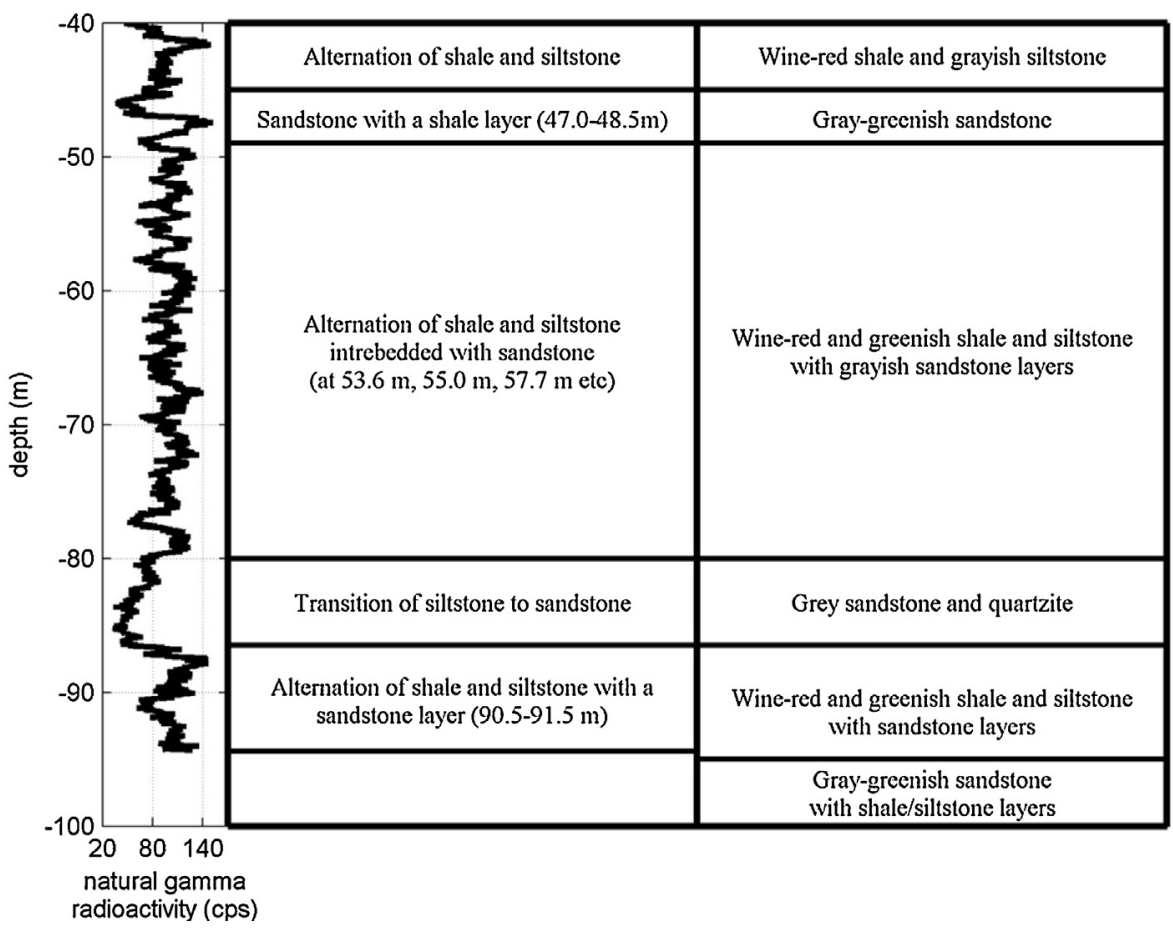

Fig. 8. Gamma-ray data (left) and geological interpretation based on gamma-ray data (middle) and cuttings observation (right) for B4.
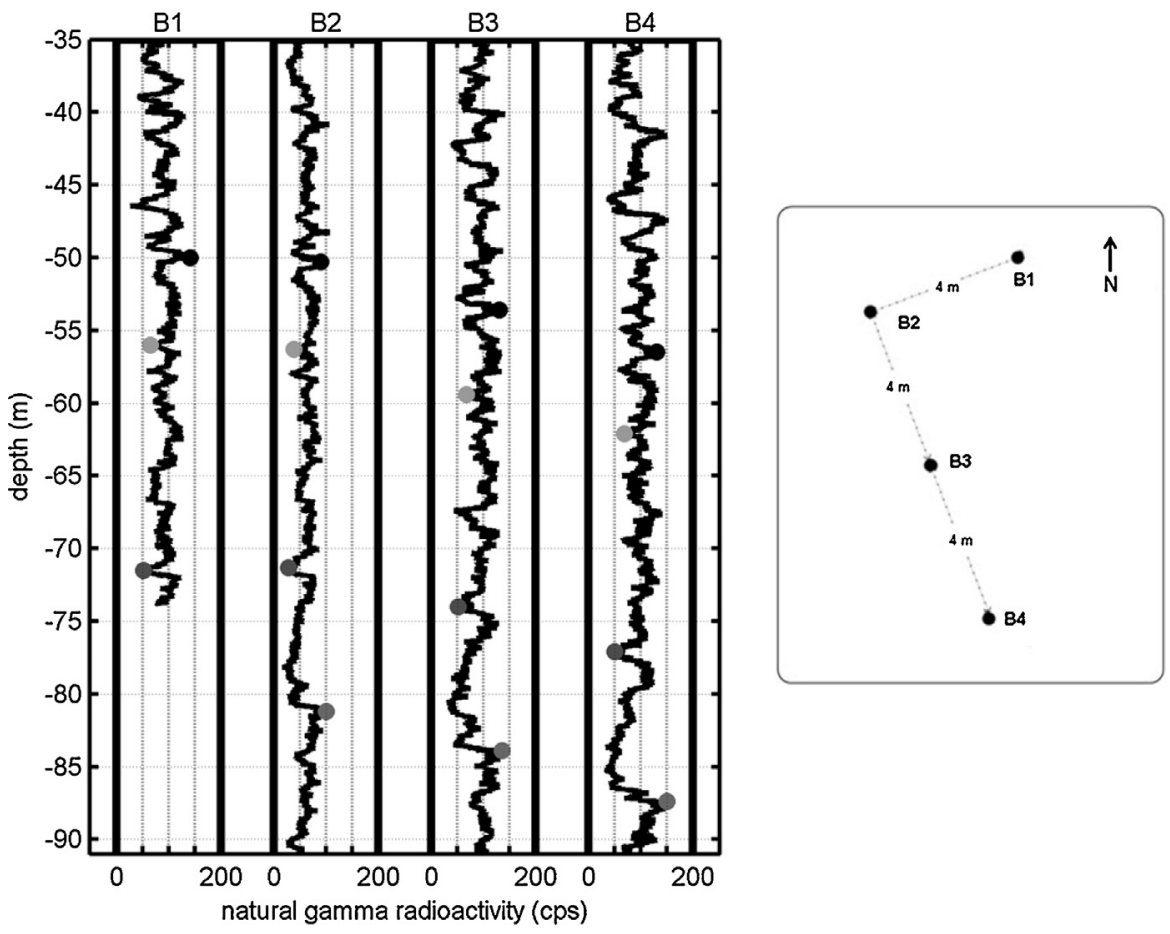

Fig. 9. Natural gamma radioactivity data for the four boreholes.

can be identified by the cuttings thermal conductivity measurements.

Each sample was assigned to a layer according to its corresponding sampling depth interval. Successive layers with low (or high) thermal conductivity values were merged into one layer. Then, the mean thermal conductivity for each layer was calculated

The results for B3 and B4 are shown in Fig. 12, where dashed lines indicate the layer dip angle. The mean layer dip angle, approximately $48^{\circ} \mathrm{SE}$, can be calculated based on these data and the relative distance between the boreholes (Table 2).
Table 2

Layer dip angle calculation based on cuttings thermal conductivity.

\begin{tabular}{llll}
\hline depth at B3 $(\mathrm{m})$ & 61.3 & 79.80 & 89.4 \\
& B3B4 & & \\
horizontal distance $(\mathrm{m})$ & 2.93 & 3.13 & 3.35 \\
elevation difference $(\mathrm{m})$ & 3.10 & 3.30 & 3.80 \\
dip angle $\left(^{\circ}\right)$ & 47.58 & 46.53 & 48.61 \\
mean dip angle $\left(^{\circ}\right)$ & 47.57 & &
\end{tabular}



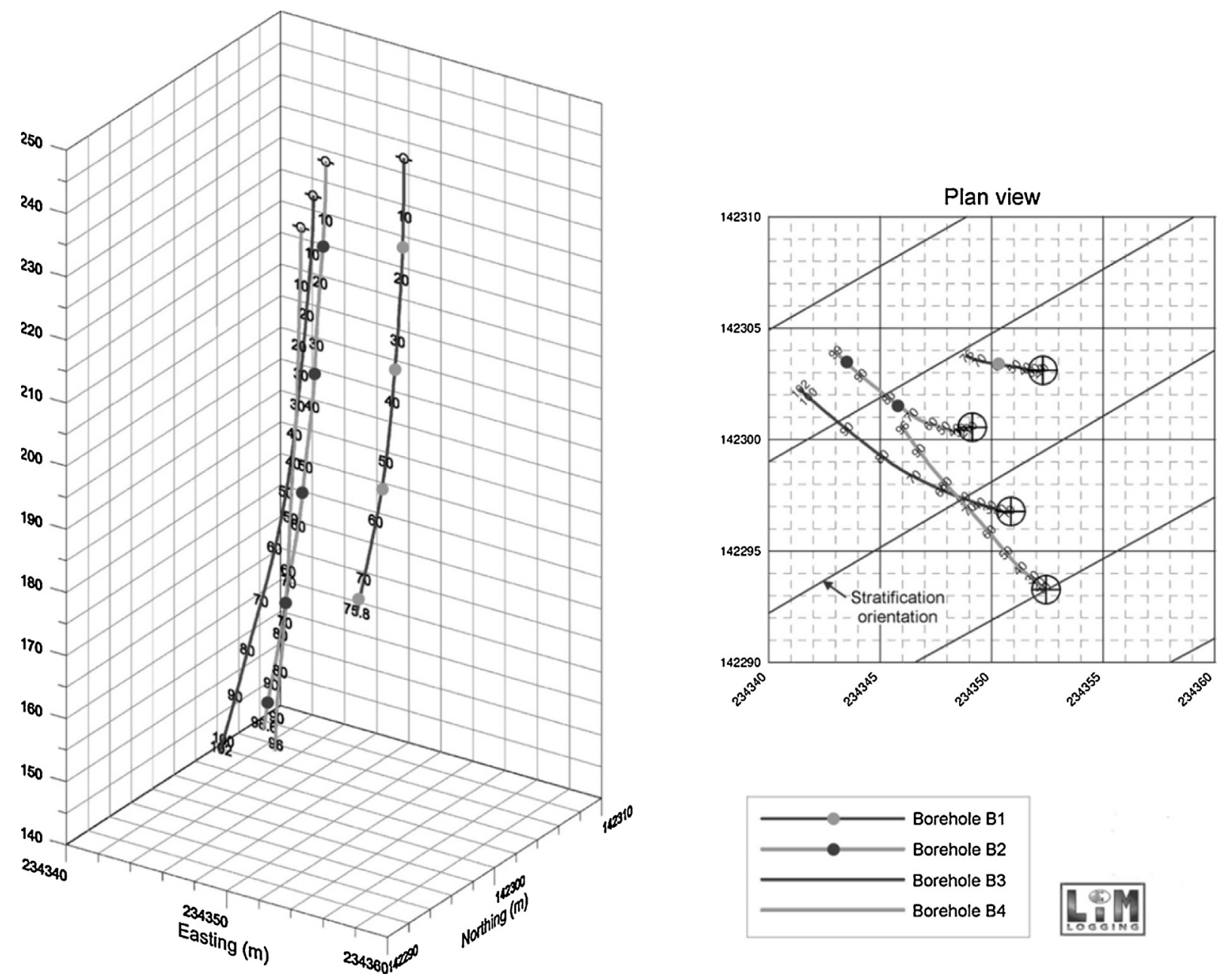

Fig. 10. Deviation of the boreholes.

B3

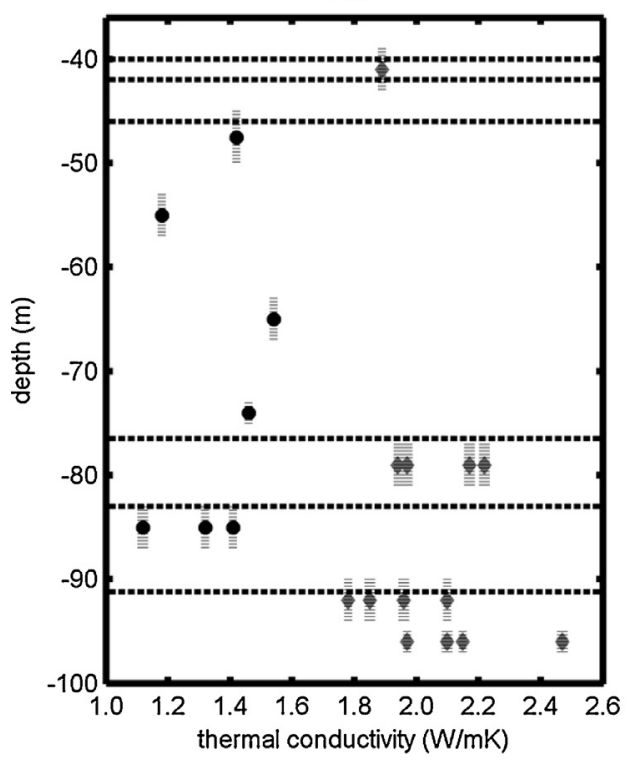

B4

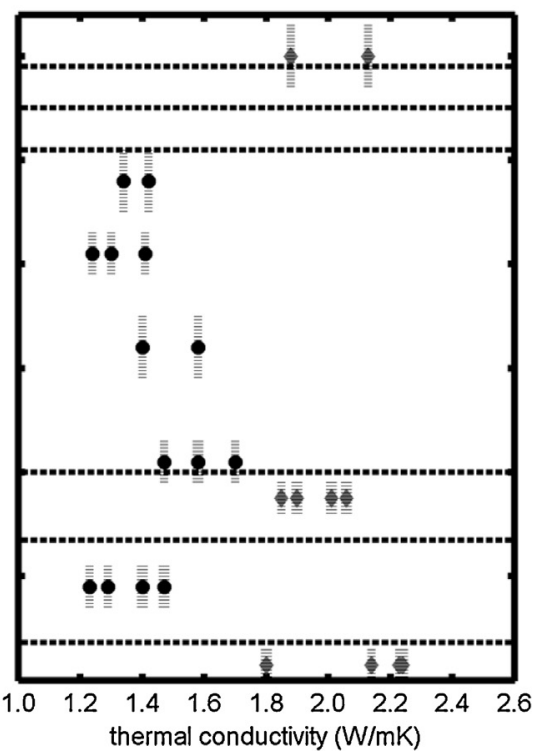

Fig. 11. Measured thermal conductivity of cuttings (dry samples) for B3 and B4.

The mean measured sandstone/siltstone and shale/siltstone thermal conductivity is equal to $2.0 \mathrm{~W} / \mathrm{mK}$ and $1.4 \mathrm{~W} / \mathrm{mK}$ respectively for both boreholes. It should be noted that cuttings thermal conductivity measurements might not be representative of the effective thermal conductivity of the rock mass in-situ. Cuttings contain no information on the rock mass fracturing, the degree of 


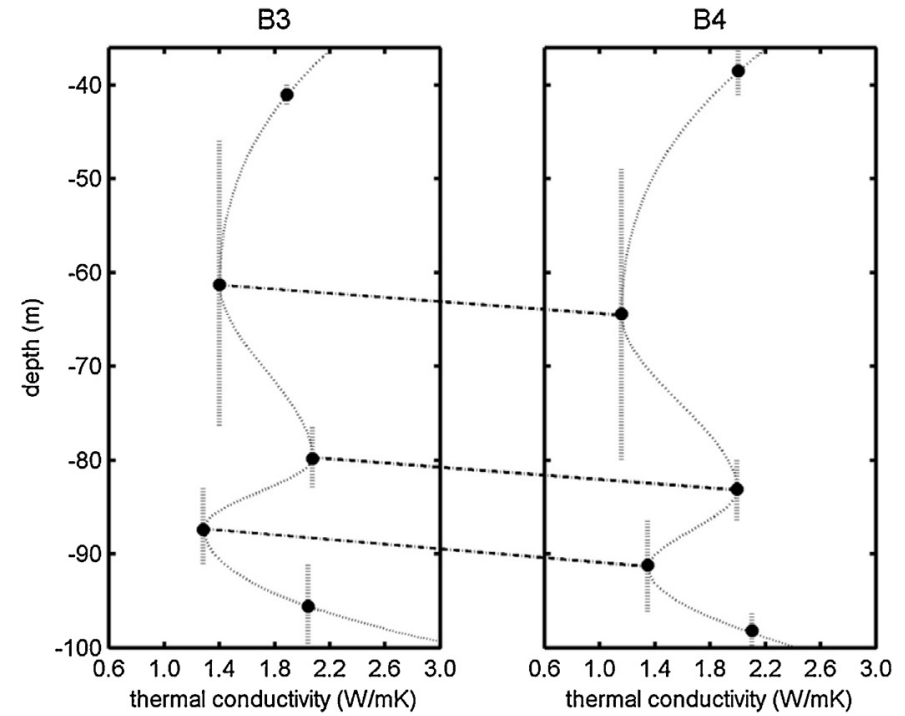

Fig. 12. Layer dipping indication based on thermal conductivity of cuttings for B3 and B4.

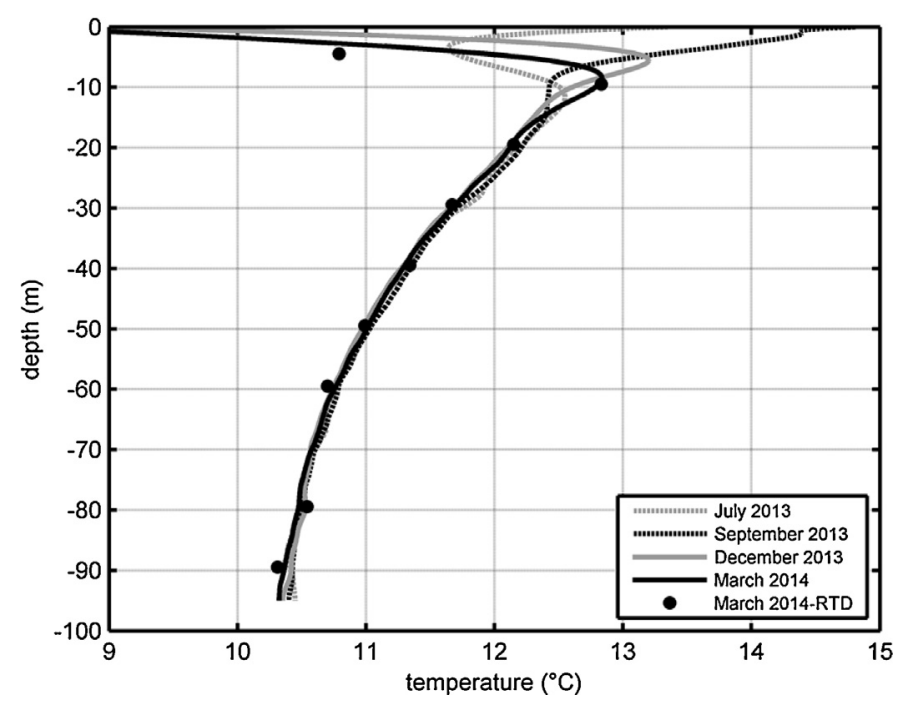

Fig. 13. Undisturbed ground temperature measured every three months for one year in $\mathrm{B} 2$.

saturation and the thermal interaction between different layers, parameters that influence the effective in-situ thermal conductivity. However, these measurements indicate a possible anisotropic thermal behaviour of the rock mass in-situ, due to alternation of different rock layers through depth, with enhanced heat transfer at mainly sandstone layers.

\subsection{DTS technique}

\subsubsection{Temperature at the undisturbed state and during hardening of the grouting material}

Temperature was recorded every $20 \mathrm{~cm}$ with a spatial resolution of $2 \mathrm{~m}$ during hardening of the grouting material, as well as several days afterwards. Fig. 13 shows the undisturbed temperature profile (existing temperature before heat injection/extraction) measured every three months for one year in B2. The first approximately $18 \mathrm{~m}$ correspond to the thermally unstable zone, where ground temperature is influenced by the outside temperature. The thermally stable zone is characterised by the absence of the geothermal gradient. At this zone temperature decreases through depth at a mean rate of

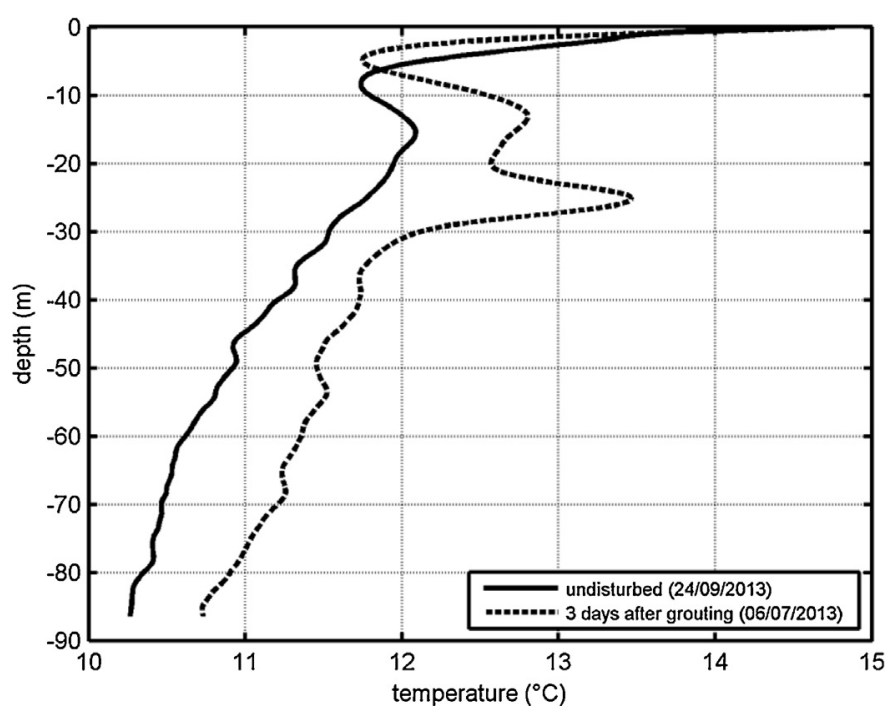

Fig. 14. Local maxima in temperature profile during hardening of the grouting material in B1.

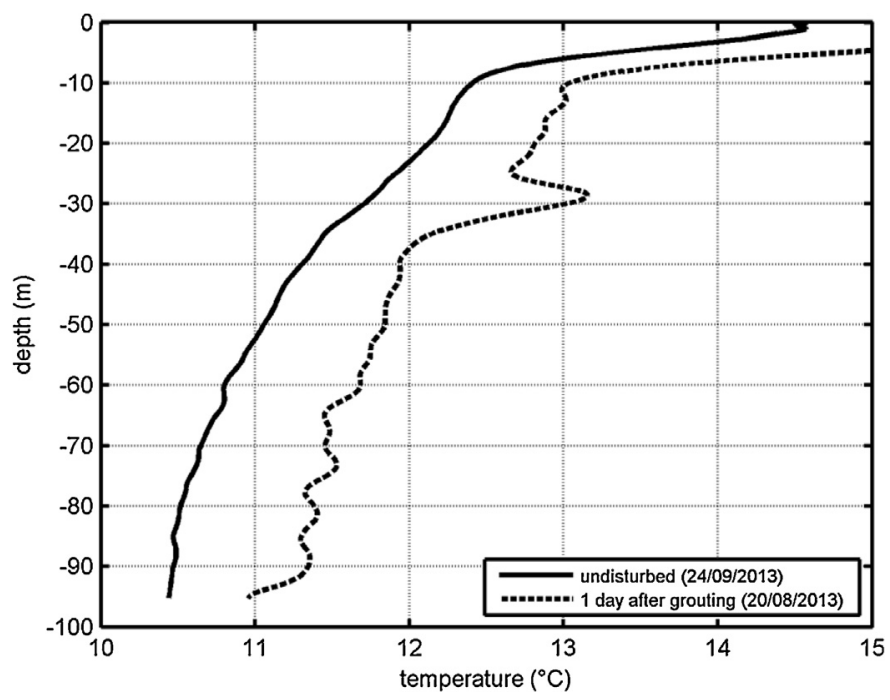

Fig. 15. Local maxima in temperature profile during hardening of the grouting material in B4.

approximately $0.25^{\circ} \mathrm{C} / 10 \mathrm{~m}$, probably due to the existence of buildings and underground structures (heating feeder pipe) close to the boreholes, that heat the surrounding ground through their foundations (Liebel et al., 2011). The temperature profiles measured in B1, B3 and B4 coincide with those of B2 for the thermally stable zone. In the thermally unstable zone, B1 displays a lower temperature compared to the other three boreholes. This could be also attributed to the relative position of the boreholes to the university feeder pipe that heats the surrounds ground, buried in the ground at an average depth of $2.5 \mathrm{~m}$ (Radioti et al., 2015b). Undisturbed temperature was also measured by applying an alternative procedure. A resistance temperature detector (tolerance class A) was slowly lowered down into one side of the loop and the temperature was measured every $10 \mathrm{~m}$. The temperature measurements from this procedure is in a very good agreement with the corresponding fiber optics profile, as shown in Fig. 13.

Heat is generated during the first hours of hardening of the grouting material, which results in a temperature increase along the borehole length. In the following days temperature retrieves its initial undisturbed profile. Figs. 14 and 15 show the temperature 
profiles after injecting the grouting material in B1 (03/07/2013) and B4 (19/08/2013) respectively. The first measurement of the undisturbed temperature profile was conducted 83 and 36 days after injecting the grouting material for B1 and B4 respectively. The temperature profiles during hardening of the grouting material are characterised by local maxima, of a significantly increased temperature value, at $26 \mathrm{~m}$ for B1 and $29 \mathrm{~m}$ for B4. These locations correspond to extended fractured zones more than one meter based on the acoustic travel time and amplitude analysis, as presented above in Section 3.1.1. These local maxima of the temperature curves are probably due to a local larger quantity of grouting material and/or local lower thermal diffusivity due to gathering of fractures (Radioti et al., 2015a).

Close to the local maxima of the temperature profile in Fig. 14, the temperature is increased between $22 \mathrm{~m}$ and $29 \mathrm{~m}$ deep. This depth difference, equal to $7 \mathrm{~m}$, corresponds to the maximum and not to the exact thickness of the fractured zone. Assuming that the thickness of the fractured zone is $2 \mathrm{~m}$ and is located between $25 \mathrm{~m}$ and $27 \mathrm{~m}$ deep (as indicated above by the logging analysis), a larger quantity of grouting material, and hence an increased heat generation, is limited between $25 \mathrm{~m}$ and $27 \mathrm{~m}$ deep. The increased temperature observed at the non-fractured zone in this case (22-25 $\mathrm{m}$ and 27-29 $\mathrm{m}$ deep) could be explained as the result of the heat transfer to the surrounding ground. Hence we can conclude that the maximum thickness of the extended fractured zone is estimated to $7 \mathrm{~m}$ (in between $22 \mathrm{~m}$ and $29 \mathrm{~m}$ depth) for B1 and $8 \mathrm{~m}$ (in between $26 \mathrm{~m}$ and $34 \mathrm{~m}$ depth) for B4.

Based on these measurements we can identify extended fractured zones, more than one meter thick for this specific case. The filled with grouting material fractures would locally affect the fracture transmissivity and hence the rock mass permeability. Moreover the grouting could locally reinforce the rock mass and modify its mechanical characteristics. Grouting materials display different thermal properties than air or water, that fill the open fractures, and hence influence the locally effective thermal properties of the rock mass. These parameters are important for the hydro-thermo-mechanical behaviour of the bedrock. Though random large fractures (more than $10 \mathrm{~cm}$ wide) or smaller fractures (of an opening between 5 and $10 \mathrm{~cm}$ ) cannot be identified by this procedure. The width of hotspots corresponding to random fractures is quite lower than the spatial resolution of the measurements $(2 \mathrm{~m})$ and the sampling interval $(20 \mathrm{~cm})$. Even if these hotspots were included in the measurement points, the measured temperature could be significantly reduced, and hence undetectable in the temperature profile.

\subsubsection{Temperature during the recovery phase of a DTRT}

Once the boreholes were drilled, the water Table was detected to be stable at $10 \mathrm{~m}$ below ground surface in all the boreholes. TRTs were conducted in-situ and the mean ground thermal conductivity was calculated based on the Infinite Line Source model by applying the forward regression technique (Tinti, 2012). The calculated thermal conductivity for B1, B3 and B4 reaches convergence after approximately $40 \mathrm{~h}$ (Fig. 16). The obtained thermal conductivity values after $40 \mathrm{~h}$ range from $2.8 \mathrm{~W} / \mathrm{mK}$ to $3.0 \mathrm{~W} / \mathrm{mK}$ for $\mathrm{B} 1$, $2.9 \mathrm{~W} / \mathrm{mK}$ to $3.2 \mathrm{~W} / \mathrm{mK}$ for $\mathrm{B} 3$ and $2.7 \mathrm{~W} / \mathrm{mK}$ for $\mathrm{B} 4$. The convergence of the conductivity curves indicates the absence of a high groundwater flow.

DTRTs were conducted in B3 and B4. In B3, a heating period of $10 \mathrm{~h}$ and a recovery period of $90 \mathrm{~h}$ were applied. Fig. 17 shows the depth-average temperature measured by the fiber optics during the test. During the heating period temperature increases from $10.9^{\circ} \mathrm{C}$ to $15.5^{\circ} \mathrm{C}, 85 \%$ of this temperature increase is recovered during the first $10 \mathrm{~h}$ of the recovery phase and more than $95 \%$ after one day.

Fig. 18 shows high-resolution temperature profiles along the pipe loop during the recovery period in B3. The temperature

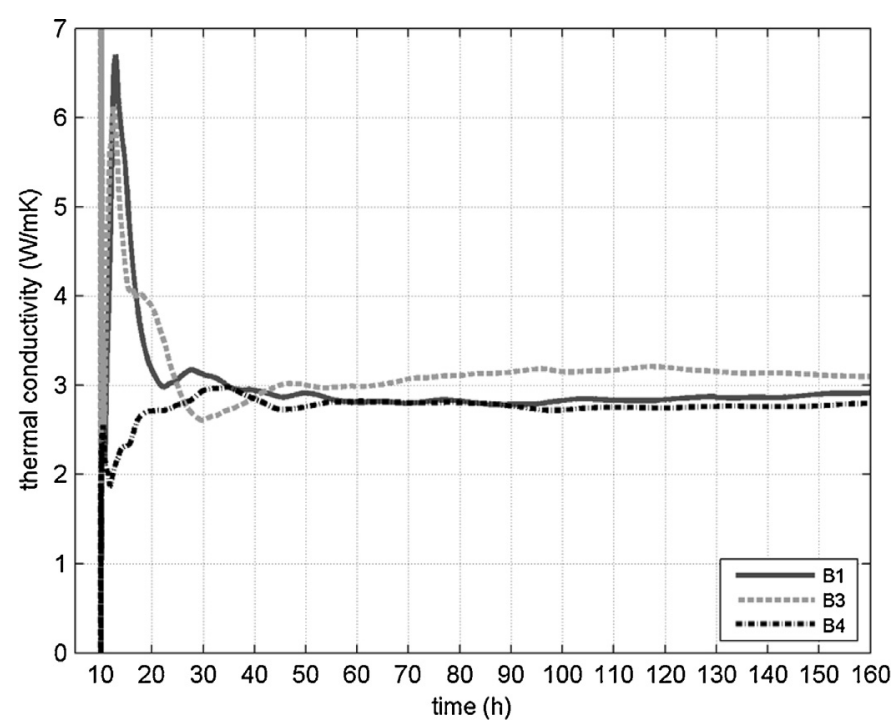

Fig. 16. Mean ground thermal conductivity in B1, B3 and B4.

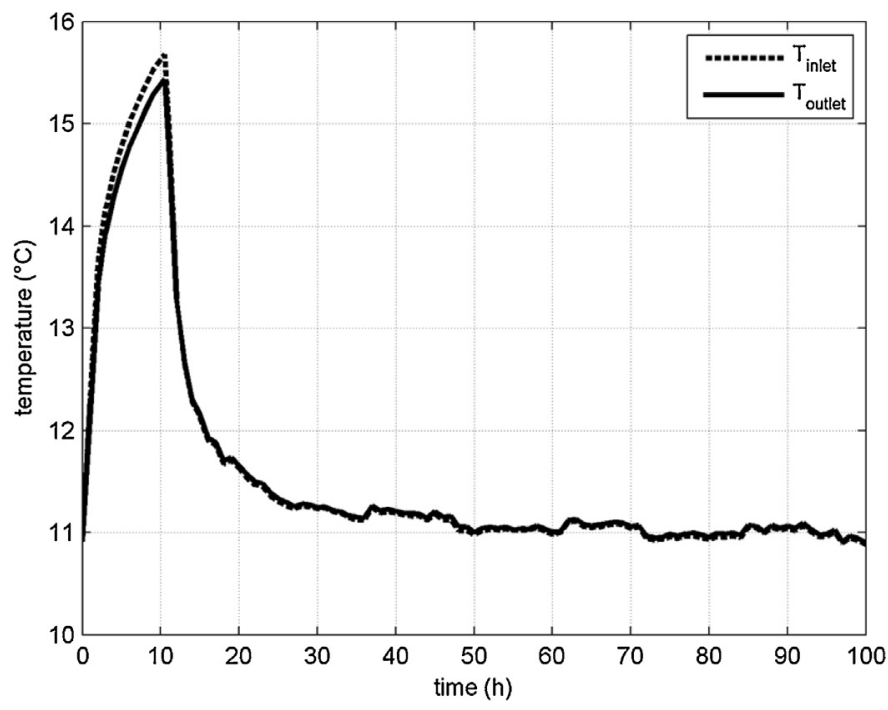

Fig. 17. Depth-average temperature evolution during the heating and the recovery phase in B3.

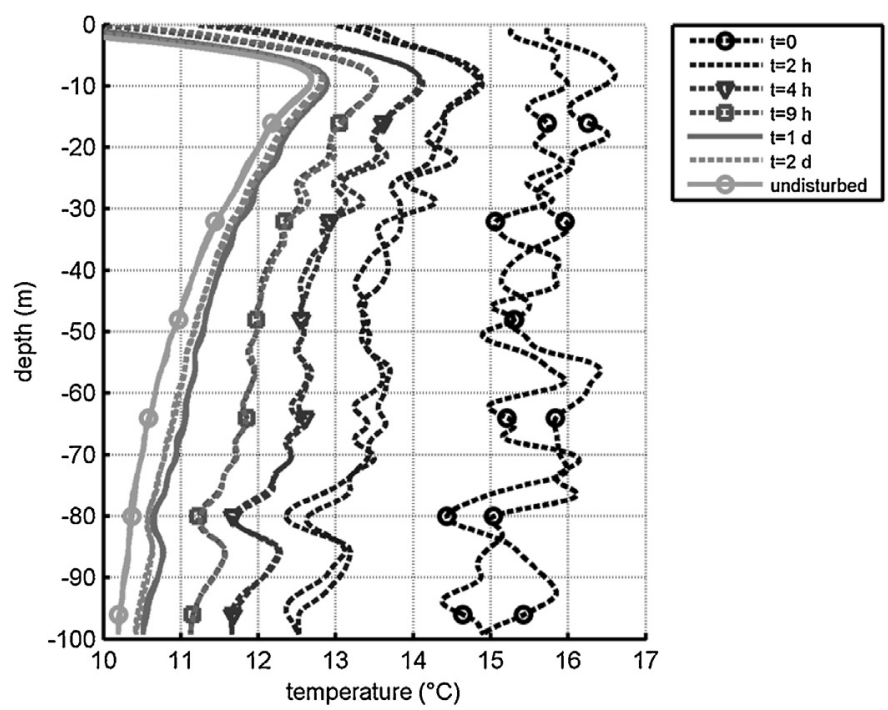

Fig. 18. Recovery temperature profiles after $10 \mathrm{~h}$ of constant heat injection in B3. 


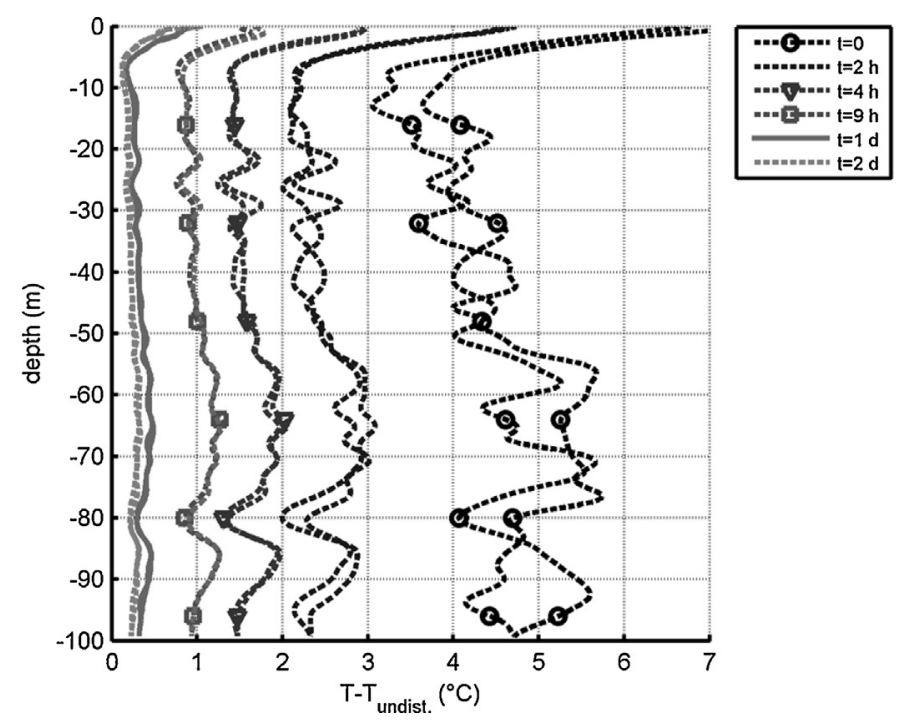

Fig. 19. Temperature difference between the recovery and the undisturbed temperature profile in $\mathrm{B} 3$.
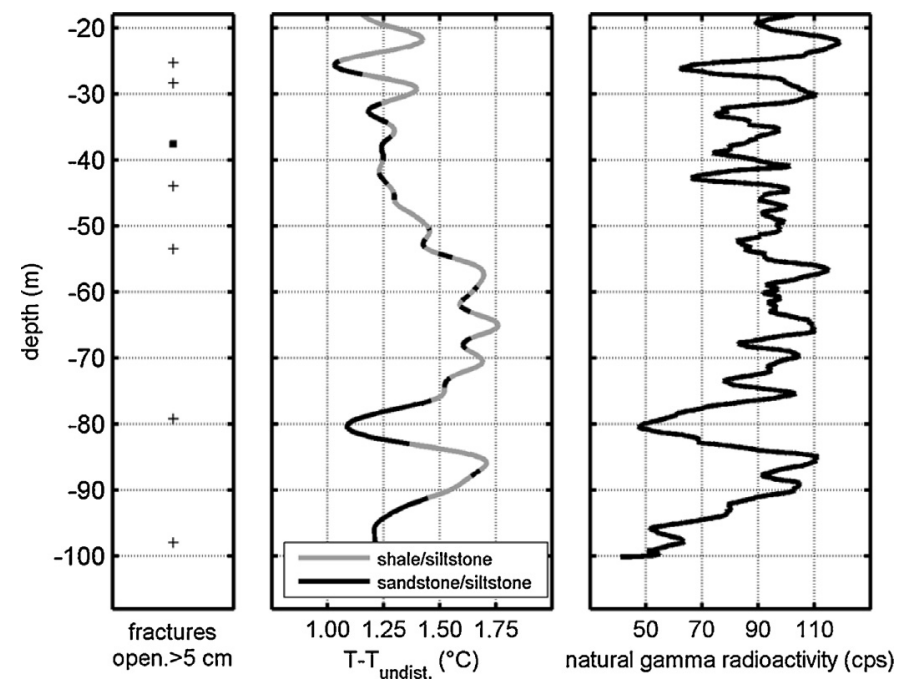

Fig. 20. Open fractures distribution, temperature difference after $4 \mathrm{~h}$ of recovery and natural gamma radioactivity data for B3.

difference between the initial $(t=0)$ and the undisturbed temperature increases through depth, due to the negative gradient of the undisturbed temperature profile. Thus, considering homogeneous geological conditions, the heat transfer rate would increase with depth during the first hours of recovery. In order to remove this effect from the measurements, the temperature difference between each recovery profile and the undisturbed temperature was calculated (Fig. 19). Local peaks in these profiles indicate an uneven heat transfer rate through depth.

In order to investigate the possible correlation of these profiles to rock characteristics, a temperature difference profile after $4 \mathrm{~h}$ of recovery is presented in Fig. 20 and compared to gamma-ray data (moving average of $2 \mathrm{~m}$ ) and fractures distribution through depth. The first $18 \mathrm{~m}$ are not included in this graph since they correspond to the thermally unstable zone. It is observed that temperature local minima correspond to gamma-ray local minima, indicating sandstone/siltstone layers, while temperature local maxima to gamma-ray local maxima, indicating shale/siltstone layers. The higher thermal diffusivity of sandstone/siltstone is evident in the in-situ measurements despite the relatively small thickness
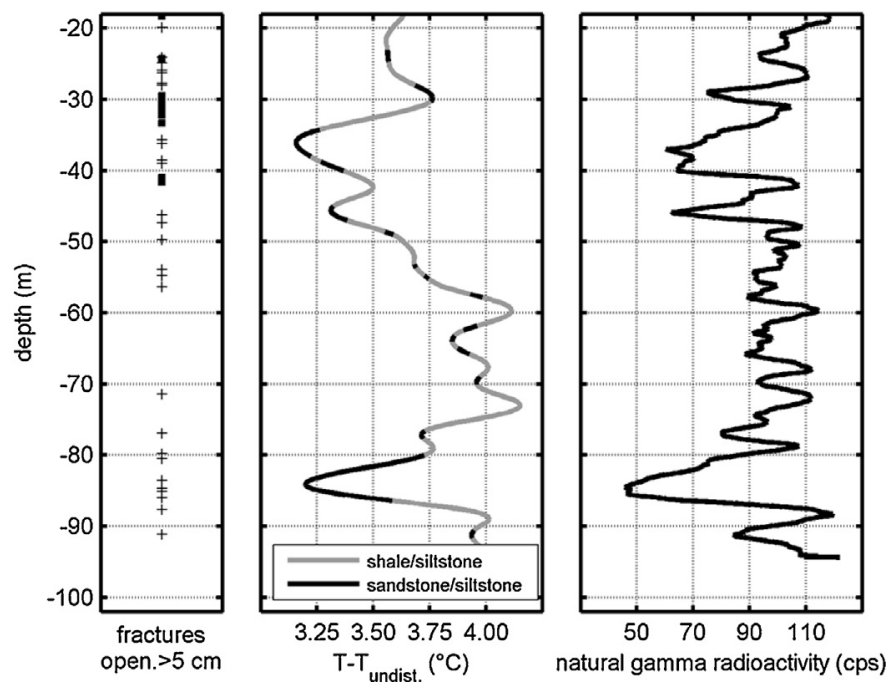

Fig. 21. Open fractures distribution, temperature difference after $4 \mathrm{~h}$ of recovery and natural gamma radioactivity data for B4.

Table 3

Layer dip angle calculation based on fiber optics temperature profiles.

\begin{tabular}{llll}
\hline depth at B3 $(\mathrm{m})$ & 57.10 & 70.5 & 80.4 \\
& B3B4 & & \\
horizontal distance $(\mathrm{m})$ & 2.87 & 2.91 & 3.15 \\
elevation difference $(\mathrm{m})$ & 2.70 & 2.80 & 3.50 \\
dip angle $\left(^{\circ}\right)$ & 43.25 & 43.93 & 48.01 \\
mean dip angle $\left(^{\circ}\right)$ & 45.06 & & \\
\hline
\end{tabular}

of these layers. The results are in good agreement with those of the gamma-ray data analysis (Section 3.1.2) and the cuttings thermal conductivity analysis (Section 3.2). B3 is characterised of a few large open fractures (opening $>5 \mathrm{~cm}$ ) and hence any correlation between the fracturing and the temperature measurements is not evident in this case.

The same procedure is applied for B4, which is quite more fractured than B3. Fig. 21 shows the temperature difference profile after $4 \mathrm{~h}$ of recovery compared to gamma-ray data (moving average of $2 \mathrm{~m}$ ) and fractures distribution through depth for B4. Temperature local peaks coincide to gamma-ray local peaks, as in B3, for depth greater than $35 \mathrm{~m}$. Though this correlation is not persistent for the upper part of the borehole where an extended fractured zone exists, between $29.4 \mathrm{~m}$ and $31.3 \mathrm{~m}$ depth, probably filled with grouting material. The quite fractured rock at this position could be characterised by a lower thermal diffusivity, due to air or grouting material filling the fractures, compared to the surrounding less/non fractured rock. Thus a local maxima is observed in the temperature profile at the depth corresponding to the fractured zone.

In both profiles, B3 and B4, sandstone/siltstone layers more than $1.2 \mathrm{~m}$ thick can be identified as local minima in the temperature profiles, while thinner layers are not always detectable. As mentioned in the case of the temperature profiles during hardening of the grouting material, local temperature changes of width smaller than the spatial resolution (equal to $2 \mathrm{~m}$ in this case) could be undetectable in the measured temperature profiles. Moreover groundwater effects are not considered in this analysis since TRTs conducted in-situ indicate the absence of high groundwater flow, as presented previously in this section.

The layer dip angle can be calculated based on the recovery profiles of B3 and B4 (Fig. 22) and the relative distance between them. The mean layer dip angle proposed by this analysis is approximately $48^{\circ} \mathrm{SE}$ (Table 3 ) and is in good agreement with those proposed by 


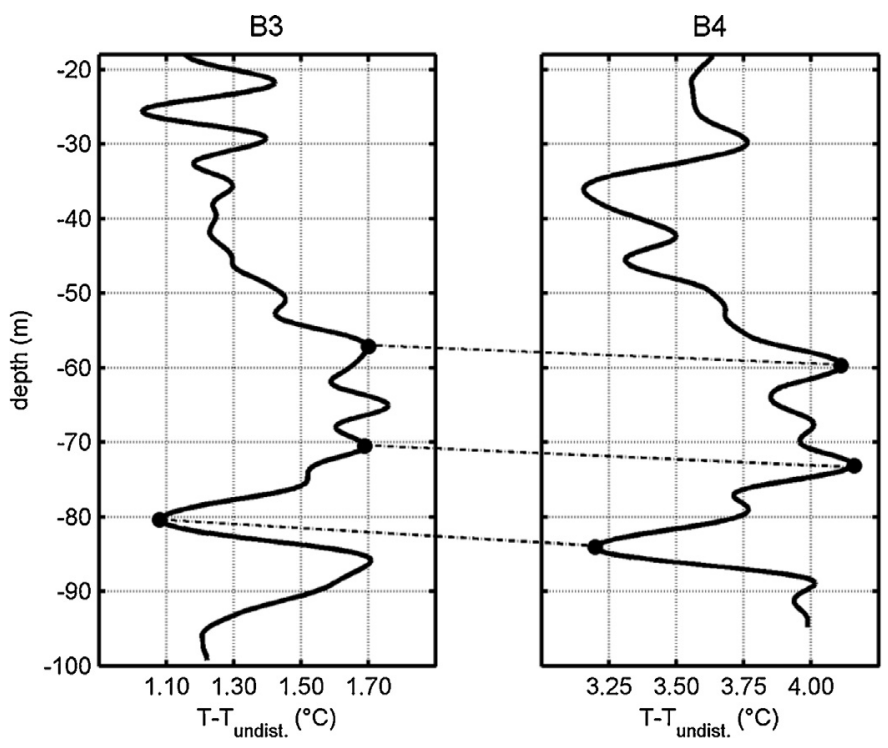

Fig. 22. Layer dipping indication based on B3 and B4 temperature measurements.

the gamma-ray data analysis (Section 3.1.3) and by the cuttings thermal conductivity analysis (Section 3.2).

\section{Discussion}

Two different analyses are presented for the fracture characterisation: the borehole logging analysis and the fiber optic temperature profiles analysis. The extended fractured zones (thickness more than $1 \mathrm{~m}$ ) location is limited between $22 \mathrm{~m}$ and $29 \mathrm{~m}$ deep for B1 and between $26 \mathrm{~m}$ and $34 \mathrm{~m}$ deep for B4, for both approaches. For B1, the middle of the fractured zone is located at a depth of $26 \mathrm{~m}$ for both approaches. The thickness of this fractured zone is $2 \mathrm{~m}$ based on the borehole logging analysis and between $1 \mathrm{~m}$ and $7 \mathrm{~m}$ based on the temperature profile analysis. For B4, two extended zones are located close to each other (between $28.0 \mathrm{~m}$ and $31.4 \mathrm{~m}$ and between 32.1 and $33.4 \mathrm{~m}$ depth) based on the logging analysis. The fiber optic temperature analysis indicates one fractured zone, coinciding with the two fractured zones of the logging analysis. Its middle is located at $29 \mathrm{~m}$ and its thickness is between $1 \mathrm{~m}$ and $8 \mathrm{~m}$. The results of both analyses are in good agreement with each other. The filled with grouting material fractures would locally affect not only the thermal but also the hydro-mechanical behaviour of the bedrock and would contribute to its possible spatial anisotropic behaviour. In the case of non-grouted wells, where temperature measurements during hardening of the grouting material cannot be obtained, water-bearing fractures could be located by measuring the temperature along the borehole during the recovery phase of a TRT (Liebel et al., 2011).

Three different approaches are presented for rock identification in this case-study: cuttings observation and gamma-ray data analysis (borehole logging), cuttings thermal conductivity analysis and fiber optic temperature profiles analysis. Based on the first approach, the exact location of thin rock layers can be detected with a resolution of $5 \mathrm{~cm}$ and three different rock types were identified (sandstone, shale and siltstone). Sandstone is mainly composed of quartz and feldspar while shale and siltstone contain a significant clay fraction. The thermal conductivity of quartz is much higher than the one of non-quartz minerals, and as a results sandstone thermal conductivity is higher than the shale and siltstone thermal conductivity. This indicates the possible anisotropic thermal behaviour in-situ due to different mineral composition of rock layers. The second approach is limited by the sampling depth interval ranging between 2 and $6 \mathrm{~m}$ in this case-study. The third approach identifies layers thicker than $1.2 \mathrm{~m}$. These layers can be easily detected in the recovery temperature profiles, by excluding the extended fractured zones, since groundwater flow effects are not dominant in this case-study. In the opposite case, driller's well reports could help to distinguish groundwater flow zones from layers of different mineral content (Liebel et al., 2011).

Three different approached are compared for the layer dip angle determination gamma-ray data analysis (borehole logging), cuttings thermal conductivity analysis and fiber optic temperature profiles analysis. The calculated mean dip angle values of the three approaches, based on B3 and B4 data, are in good agreement with each other (maximum difference of $6 \%$ ). The borehole logging approach for B2 and B3 results in the same dip angle as for B3 and B4. Moreover the calculated layer dip angle values are included in the discontinuities dip angle range $\left(40-70^{\circ}\right)$ as indicated by the stereographic interpretation.

The temperature difference between the profile during hardening of the grouting material and the undisturbed temperature in B4 is presented in Fig. 23, together with the temperature difference profile after $4 \mathrm{~h}$ of recovery and the gamma-ray data. It is observed that after $40 \mathrm{~m}$ depth temperature local maxima coincide with local maxima of the recovery profile which correspond to gamma-ray local maxima, indicating shale/siltstone layers. These local maxima are significantly lower than the one at $29 \mathrm{~m}$ which corresponds to the fractured zone.

\section{Conclusions}

A bedrock heterogeneity investigation is presented based on in-situ and laboratory geophysical measurements. Temperature profiles during hardening of the grouting material allow us to locate extended fracture zones, more than one meter in this specific case. The profiles during hardening of the grouting material were obtained at different time period in B1 and B4 after injecting the grouting material. Hence a behaviour comparison between the two types of the grouting cannot be deduced by these measurements. More measurements or a continuous monitoring could provide information on the behaviour of different grouting materials during hardening, as well as on the required time for the temperature to retrieve its initial profile after the BHE installation.

Based on temperature measurements during the recovery phase of a DTRT we can detect layers with different mineral content since they display a different thermal behaviour. Layers thinner than $1.2 \mathrm{~m}$ or random fractures cannot be identified by this procedure. The resolution of the applied procedure is limited by the measurement parameters, spatial resolution and sampling interval. Lower spatial resolution and sampling interval in combination to a longer-duration heating phase of the TRT could improve the resolution of the results. Investigation of more than one boreholes in a limited rock mass can contribute significantly to bedrock heterogeneity knowledge. Comparison of the boreholes temperature profiles results in determination of the layer dipping.

Based on the cuttings thermal conductivity the transition of one formation to another and the layer dipping is indicated, since in this case their different mineral composition results in a different thermal conductivity. This approach is easy to implement, but is not applicable if a limited quantity of cuttings is available or in the case of soil layers. Cuttings measurements should be studied qualitatively for extrapolating them to in-situ conditions. Cuttings contain no information on the rock mass fracturing, the degree of saturation and the thermal interaction between different layers, parameters that influence the effective in-situ thermal behaviour.

It is also possible to conclude that, given the increasing number of closed-loop geothermal systems in Walloon region and Europe and the wide application of TRTs, it would be of interest in any $\mathrm{BHE}$ to measure the temperature during hardening of the grouting 

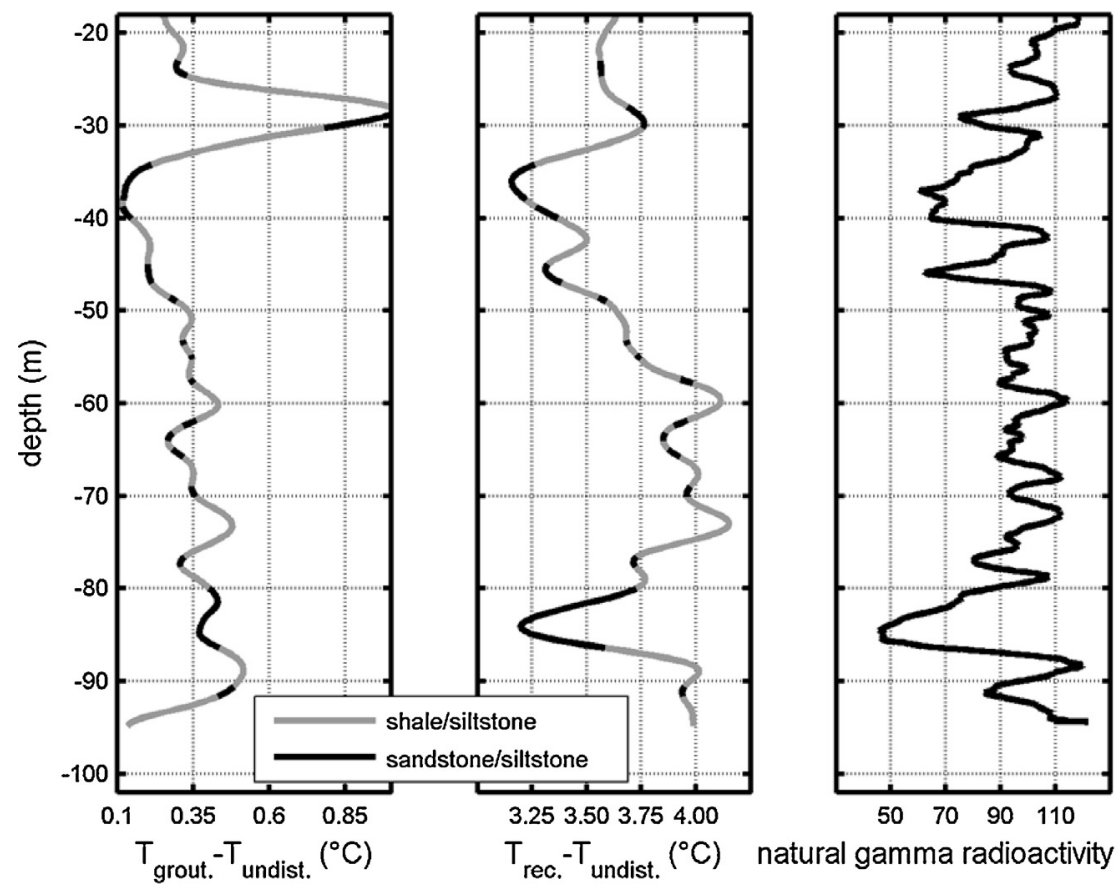

natural gamma radioactivity (cps)

Fig. 23. Temperature difference of the profile during hardening of the grouting material, after $4 \mathrm{~h}$ of recovery and natural gamma radioactivity data for B4.

material and after $4 \mathrm{~h}$ of recovery. Alternatively to fiber optic cables, a temperature sensor (e.g. thermocouple element, resistance temperature detector) can simply be lowered down into the pipe to obtain the temperature profiles. This approach is cost-effective and easy to implement and would give valuable information about the rock nature and stratification, as well as about the rock geothermal reservoir potential. In combination to a mathematical model or advanced numerical modelling, this approach could contribute to the long-term behaviour prediction of closed-loop geothermal systems and to optimisation of their efficiency. Ongoing work includes research for predicting the system behaviour by taking into account the impact of heterogeneity based on this characterisation study.

\section{Acknowledgements}

The work undertaken in this paper is supported by the Walloon Region project Geotherwal n 1117492 and the F.R.S.-FNRS F.R.I.A. fellowship of Georgia Radioti. We also would like to thank the University service ARI for their support in the installation of the BHEs as well as our partners in the project, the ULB (Universite Libre de Bruxelles) and the companies OREX and Geolys. We thank the company REHAU for providing the pipes and the commercial grouting materials.

\section{References}

ASTM D 5334-00, 2000. Standard Test Method for Determination of Thermal Conductivity of Soil and Soft Rock by Thermal Needle Probe Procedure. ASTM International, West Conshohocken, PA (04.08 19428-2059).

Acuña, J., 2010. Improvements of U pipe borehole heat exchangers. In: Doctoral Thesis. KTH School of Industrial Engineering and Management, Stockholm.

Alonso-Sánchez, T., Rey-Ronco, M.A., Carnero-Rodríguez, F.J., Castro-García, M.P., 2012. Determining ground thermal properties using logs and thermal drill cutting analysis. First relationship with thermal response test in principality of Asturias, Spain. Appl. Therm. Eng. 37, 226-234.

Bradbury, K.K., Barton, D.C., Solum, J.G., Draper, S.D., Evans, J.P., 2007. Mineralogic and textural analyses of drill cuttings from the San Andreas Fault Observatory at Depth (SAFOD) boreholes: initial interpretations of fault zone composition and constraints on geologic models. Geosphere 3 (5), 299-318, http://dx.doi. org/10.1130/GES00076.1.

Bultynck, P., Coen-Aubert, M., Dejonghe, L., Godefroid, J., Hance, L., Lacroix, D., Preat, A., Stainier, P., Steemans, P., Streel, M., Tourneur, F., 1991. Les formations du Dévonien Moyen de la Belgique. Mémoires pour servir à l'explication des Cartes Géologiques et Minières de la Belgique, vol. 30. Ministère des affaires économiques, Bruxelles.

Calembert, L., Pel, J., Brumagne, D., 1964. Géologie. Extrait du 2ième cahier du Sart Tilman, Publication no. 25, Laboratoires de Géologie de la Fac. des Sc. Appl.,Université de Liège.

Calembert, L., Monjoie, A., Polo-Chiapolini, Cl., préface par De Beer, E., 1975. Carte géotechnique prototype du sart tilman. Annales des Travaux Publics de Belgique 5, 5.

Clauser, C., Huenges, E., 1995. Thermal Conductivity of Rocks and Minerals. Rock Physics and Phase Relations-A Handbook of Physical Constants, Vol. 3. AGU Reference Shelf.

Corteel, C., Van Den Houte, P., Verniers, J., 2004. New sedimentological and petrographical observations on the Devonian Burnot Formation in the Belgian Rhenohercynian basin. Geologica Belgica 7, 41-53.

Dakin, J.P., Pratt, D.J., 1985. Distributed optical fibre Raman temperature sensor using a semiconductor light source and detector. Electron. Lett. 21, 569-570.

Erol, S., François, B., 2014. Efficiency of various grouting materials for borehole heat exchangers. Appl. Therm. Eng. 70, 788-799.

Fuchs, S., Förster, A., 2010. Rock thermal conductivity of Mesozoic geothermal aquifers in the Northeast German Basin. Chem. Erde-Geochem. 70 (S3), 13-22.

Fujii, H., Okubo, H., Itoi, R., 2006. Thermal response tests using optical fiber thermometers. GRC Trans. 30, 545-551.

Fujii, H., Okubo, H., Nishi, K., Itoi, R., Ohyama, K., Shibata, K., 2009. An improved thermal response test for U-tube ground heat exchanger based on optical fiber thermometers. Geothermics 38, 399-406.

Gehlin, S., 2002. Thermal response test-method, development and evaluation. In: Doctoral Dissertation. Luleå University of Technology, Sweden.

Guéguen, Y., Palciauskas, V., 1994. Introduction to Physics of Rocks. Princeton University Press.

Hoffmann, L., Müller, M.S., Krämer, S., Giebel, M., Schwotzer, G., Wieduwilt, T., 2007. Applications of fibre optic temperature measurement. Proc. Estonian Acad. Sci Eng. 13 (4), 363-378.

Kömle, N.I., Huetter, E.S., Feng, W.J., 2010. Thermal conductivity measurements of coarse-grained gravel materials using a hollow cylindrical sensor. Acta Geotech. 5, 211-223.

Keys, W.S., 1990. Borehole geophysics applied to ground-water investigations. In: U.S. Geological Survey Techniques of Water-Resources Investigations, book 2 , ch. E-2.

Laloui, L., Moreni, M., Vulliet, L., 2003. Comportement dun pieu bi-fonction, fondation et echangeur de chaleur. Can. Geotech. J. 40 (2), 388-402.

Liebel, H.T., Huber, K., Frengstad, B.S., Kalskin Ramstad, R., Brattli, B., 2010. Rock core samples cannot replace thermal response tests-a statistical comparison based on thermal conductivity data from the Oslo Region (Norway). Proceedings of Renewable Energy Research Conference, 10.

Liebel, H.T., Huber, K., Frengstad, B.S., Ramstad, R.K., Brattli, B., 2011. Temperature footprint of a thermal response test can help to reveal thermogeological information. Norges geologiske undersøkelse Bulletin 451, 20-31.

Monier-Williams, M.E., Davis, R.K., Paillet, F.L., Turpening, R.M., Sol, S.J.Y., Schneider, G.W., 2009. Review of Borehole Based Geophysical Site Evaluation 
Tools and Techniques. Nuclear Waste Management Organization, Toronto, Canada.

Paillet, F.L., Barton, C., Luthi, S., Rambow, F., Zemanek, J.R., 1990. Borehole imaging and its application in well logging - an overview. In: Borehole Imaging. Society of Professional Well Log Analysts (3-23).

Pechnig, R., Mottaghy, D., Arnold, J., Koch, A., Jorand, R., 2010. Thermal Properties of Paleozoic Rocks from the Rhenish Massif. European Geoscience Union, General Assembly, Vienna, Austria.

Popov, Y.A., Pribnow, D.F.C., Sass, J.H., Williams, C.F., Burkhardt, H., 1999. Characterization of rock thermal conductivity by high-resolution optical scanning. Geothermics 28, 253-276.

Radioti, G., Charlier, R., Nguyen, F., Radu, J.-P., 2013. Thermal response test in borehole heat exchangers equipped with fiber optics. Proceedings, International Workshop on Geomechanics and Energy: The Ground as Energy Source and Storage, 96-100.

Radioti, G., Delvoie, S., Radu, J.-P., Nguyen, F., Charlier, R., 2015a. Fractured bedrock investigation by using high-resolution borehole images and the Distributed
Temperature Sensing technique. ISRM Congress 2015 Proceedings-Int'l Symposium on Rock Mechanics.

Radioti, G., Delvoie, S., Sartor, K., Nguyen, F., Charlier, R., 2015b. Fiber-optic temperature profiles analysis for closed-loop geothermal systems: a case study. Proceedings, Second EAGE Workshop on Geomechanics and Energy: The Ground as Energy Source and Storage.

Soto, M.A., Sahu, P.K., Faralli, S., Bolognini, G., Di Pasquale, F., Nebendahl, B., Rueck C., 2007. Distributed temperature sensor system based on Raman scattering using correlation-codes. Electron. Lett. 43 (16), 862-864.

Tinti, F., 2012. The probabilistic characterization of underground as a tool for the optimization of integrated design of shallow geothermal systems. In: Doctoral Dissertation. University of Bologna, Italy.

Williams, J.H., Johnson, C.D., 2004. Acoustic and optical borehole-wall imaging for fractured-rock aquifer studies. J. Appl. Geophys. 55 (1-2), 151-159.

Zemanek, M.D., Glenn, E.E., Norton, L.J., Caldwell, R.L., 1970. Formation evaluation by inspection with the borehole televiewer. Geophysics 35, 254-269. 